\title{
First-row Transition Metal Antimonates for the Oxygen Reduction Reaction
}

G. T. Kasun Kalhara Gunasooriyaa,\#, Melissa E. Kreider2,3,\#, Yunzhi Liu4, José A. Zamora Zeledón²,3, Zhenbin Wang1, Eduardo Valle,2,3, An-Chih Yang2,3, Alessandro Gallo²,3, Robert Sinclair ${ }^{4}$, Michaela Burke Stevens ${ }^{2,3, *}$, Thomas F. Jaramillo ${ }^{2,3, *}$, Jens K. Nørskov ${ }^{1, *}$

${ }^{1}$ Catalysis Theory Center, Department of Physics, Technical University of Denmark, 2800 Kongens Lyngby, Denmark

${ }^{2}$ Department of Chemical Engineering, Stanford University 443 via Ortega, Stanford, California 94305, United States

${ }^{3}$ SUNCAT Center for Interface Science and Catalysis, SLAC National Accelerator Laboratory, Menlo Park, California 94025, United States

${ }^{4}$ Department of Materials Science and Engineering, Stanford University, 496 Lomita Mall, Stanford, California 94305, United States

\#Authors contributed equally

`E-mail: mburkes@stanford.edu, jaramillo@stanford.edu, jkno@dtu.dk 


\section{Abstract}

The development of inexpensive and abundant catalysts with high activity, selectivity, and stability for the oxygen reduction reaction (ORR) is imperative for the widespread implementation of fuel cell devices. Herein, we present a combined theoreticalexperimental approach to discover and design first-row transition metal antimonates as promising electrocatalytic materials for the ORR. Theoretically, we identify first-row transition metal antimonates $-\mathrm{MSb}_{2} \mathrm{O}_{6}$, where $\mathrm{M}=\mathrm{Mn}, \mathrm{Fe}, \mathrm{Co}$, and $\mathrm{Ni}-$ as non-precious metal catalysts with promising oxygen binding energetics, conductivity, thermodynamic phase stability and aqueous stability. Among the considered antimonates, $\mathrm{MnSb}_{2} \mathrm{O}_{6}$ shows the highest theoretical ORR activity based on the $4 \mathrm{e}^{-}$ORR kinetic volcano. Experimentally, nanoparticulate transition metal antimonate catalysts are found to have a minimum of a 2.5-fold enhancement in intrinsic mass activity (on transition metal mass basis) relative to the corresponding transition metal oxide at $0.7 \mathrm{~V}$ vs $\mathrm{RHE}$ in $0.1 \mathrm{M} \mathrm{KOH}$. $\mathrm{MnSb}_{2} \mathrm{O}_{6}$ is the most active catalyst under these conditions, with a 3.5 -fold enhancement on a per Mn mass activity basis and 25 -fold enhancement on a surface area basis over its antimony-free counterpart. Electrocatalytic and material stability are demonstrated over a $5 \mathrm{~h}$ chronopotentiometry experiment in the stability window identified by Pourbaix analysis. This study further highlights the stable and electrically conductive antimonate structure as a promising framework to tune the activity and selectivity of non-precious metal oxide active sites for ORR catalysis.
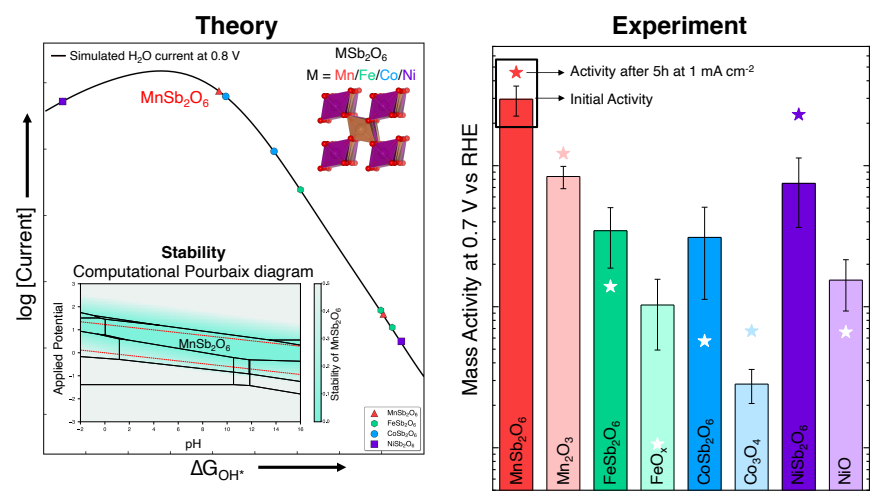


\section{Introduction}

Fuel cells are a promising class of energy conversion devices for transforming chemical energy to electricity. ${ }^{1}$ Coupled with hydrogen from renewable energy, these devices are particularly attractive for future transportation and stationary power sectors owing to their high energy efficiency, ease of operation, fast refueling, and zero emissions. ${ }^{2} \mathrm{~A} \mathrm{H}_{2}$-fuel cell device consists of two half-cell reactions: the reduction of $\mathrm{O}_{2}$ at the cathode, and the oxidation of $\mathrm{H}_{2}$ at the anode. Although this technology has been around for many decades, its performance is still hindered by several challenges, including the sluggish kinetics of the oxygen reduction reaction (ORR) at the cathode, which governs the overall efficiency of fuel cells. To date, the most efficient catalysts for the ORR are platinum (Pt)based materials supported on carbon. ${ }^{2-5}$ However, Pt-based catalysts have significant energy losses and are further limited in part because of the high cost and scarcity of $\mathrm{Pt}$, as well as insufficient durability of the catalysts under operating conditions. ${ }^{3,5}$ To address this challenge, the discovery and development of stable, active, selective, and costeffective Pt-free ORR catalysts is imperative.

Extensive studies have been carried out over the past decades to examine a wide range of Pt-free materials as next generation ORR catalysts, including Pt-free transition metal (TM) alloys and intermetallics, transition metal-nitrogen-carbon ( $\mathrm{M}-\mathrm{N}-\mathrm{C})$ catalysts, where $\mathrm{M}=\mathrm{Fe}$ or $\mathrm{Co}$, and transition metal oxides, nitrides, carbides, phosphides, and chalcogenides. ${ }^{4,6-8}$ Though some of these materials have shown ORR activity approaching that of commercial Pt-based catalysts, their application in polymer electrolyte membrane fuel cell devices has been hampered due to stability issues. ${ }^{9,10}$ An emerging technological alternative is the anion exchange membrane fuel cell, which operates at higher $\mathrm{pH}$, allowing for a wider range of stable materials. In alkaline conditions, transition metal oxide catalysts have shown a reasonable performance for the ORR., ${ }^{7,8,11-14}$ For these catalysts, efforts have focused on utilizing frameworks such as perovskites to tune the oxidation state and coordination of the transition metal active site to improve activity, stability, and selectivity to the $4 \mathrm{e}^{-}$ORR..$^{15}$ Recently, the family of first-row transition metal antimonates $-\mathrm{MSb}_{2} \mathrm{O}_{6}$, where $\mathrm{M}=\mathrm{Mn}$, $\mathrm{Fe}, \mathrm{Co}$, and $\mathrm{Ni}$ - have gained interest as electrocatalysts for a related reaction, the oxygen evolution reaction (OER), due to their unique properties, such as high electrical and thermal conductivities, tailorable electronic features, high melting points, exceptional hardness, and chemical resistance to corrosion. ${ }^{16-21}$ In particular, $\mathrm{Mn}, \mathrm{Ni}-\mathrm{Mn}$, and Co antimonates have shown significant activity for the OER. ${ }^{17-19}$ These promising results for the OER motivate the investigation of first-row transition metal antimonates for the ORR, which, to the best of our knowledge, has not been previously reported.

Herein, we use both theory and experiments to systematically study the activity, selectivity, stability, and nature of first-row transition metal antimonate electrocatalysts for 
ORR. Using density functional theory (DFT), we determine the unique surface terminations and active sites, the realistic coverages under ORR conditions, and kinetically-determined activities of $\mathrm{Mn}, \mathrm{Fe}, \mathrm{Co}$, and $\mathrm{Ni}$ antimonates for the ORR, in comparison with pure metal oxides. Experimentally, these catalysts are synthesized and rigorously characterized to understand the effect of the antimonate framework on material properties. The synthesized nanoparticulate antimonates are found to have enhanced intrinsic activity relative to their corresponding oxides in alkaline environments. Employing Pourbaix, electrochemical, and material analysis, the antimonates are found to be stable for the ORR under alkaline conditions. Overall, the first-row transition metal antimonates are found to be a promising class of materials for ORR and the antimonate structure is highlighted as a framework for rationally tuning transition metal utilization and selectivity.

\section{Methods}

\subsection{Computational Details}

Periodic spin-polarized density functional theory (DFT) calculations were performed using the RPBE exchange correlational functional, ${ }^{22}$ a plane-wave basis set with a cut-off kinetic energy of $500 / 400 \mathrm{eV}$ for bulk/surface calculations, and the projector-augmented wave (PAW) method as implemented in the Vienna Ab-initio Simulation Package (VASP version 5.4.4).23,24 PAW pseudopotentials and Hubbard $U$ correction values of $3.9 \mathrm{eV}$ 'Mn', $5.3 \mathrm{eV}$ 'Fe', $3.32 \mathrm{eV}$ 'Co', $6.2 \mathrm{eV}$ 'Ni' were selected according to the Materials Project (MP) database. ${ }^{25}$ The electronic convergence criterion was $10^{-4} \mathrm{eV}$, while the force criterion for geometry relaxation was $0.05 \mathrm{eV}^{-1}$. $\Gamma$-centered k-point grid of 50/a $\times 50 / \mathrm{b}$ $\times 50 / \mathrm{c}$ and $30 / \mathrm{a} \times 30 / \mathrm{b} \times 1$ with non-integer values rounded up to the nearest integer were used for bulk and slab calculations, respectively. In all the slabs, the bottom half of the slab in the vertical z-direction was constrained at the bulk positions, while the top half of the slab and the adsorbed species were fully relaxed. The slabs were separated in the perpendicular z-direction by $12 \AA$ of vacuum, and a dipole correction was applied. All crystal structure manipulations and data analysis were carried out using the Python Materials Genomics package (Pymatgen) ${ }^{26}$ and Atomic Simulation Environment (ASE). ${ }^{27}$

ORR catalytic activities of the different surfaces were evaluated based on the recently developed $4 \mathrm{e}^{-}$ORR kinetic volcano using the microkinetic model for oxides and based on the theoretical thermodynamic limiting potential $\left(\mathrm{U}_{\mathrm{L}}\right)$, defined as the highest potential at which all the reaction steps become exergonic by assuming an associative reaction mechanism with $\mathrm{OOH}^{*}, \mathrm{O}^{*}$, and $\mathrm{OH}^{*}$ as reaction intermediates. ${ }^{14,28}$ The computational hydrogen electrode ( $\mathrm{CHE}$ ) was used to express the chemical potential of the protonelectron pair $\left(\mathrm{H}^{+}+\mathrm{e}^{-}\right)$, which relates chemical potential of the proton-electron pair with chemical potential of gas-phase $\mathrm{H}_{2}$ molecule based on the equilibrium $\mu\left[\mathrm{H}^{+}\right]+\mu\left[e^{-}\right]=$

$\frac{1}{2} \mu\left[H_{2}(g)\right]$ at $0 U_{\mathrm{RHE}}$ (where RHE is the reversible hydrogen electrode) and corrects the 
driving force with the deviation of the applied potential from the equilibrium situation. ${ }^{28}$ In order to avoid the use of $\mathrm{O}_{2}$ electronic energy, which is difficult to determine accurately within standard GGA-DFT, the experimental free energy of $2 \mathrm{H}_{2} \mathrm{O} \rightarrow \mathrm{O}_{2}+2 \mathrm{H}_{2}, \Delta \mathrm{G}=4.92$ $\mathrm{eV}$ was used. The adsorption free energies of these ORR reaction intermediates $\left(\Delta \mathrm{Go}^{*}\right.$, $\Delta \mathrm{GOH}^{*}$, and $\left.\Delta \mathrm{GOOH}^{*}\right)$ are calculated as $\Delta \mathrm{G}_{\text {adsorption }}=\Delta \mathrm{E}_{\mathrm{DFT}}+\Delta \mathrm{E}_{\mathrm{ZPE}}+\int_{0}^{298.15} C_{p} d T-\mathrm{T} \Delta \mathrm{S}$, where $\Delta \mathrm{EDFT}_{\mathrm{DF}}$ is the difference in DFT calculated electronic energy, $\Delta \mathrm{EZPE}_{\mathrm{Z}}$ is the difference

in zero-point energies, $\int_{0}^{298.15} C_{p} d T$ is the difference in integrated heat capacity from 0 to $298.15 \mathrm{~K}, \Delta \mathrm{S}$ is the change in entropy of the adsorbed species, and calculated with respect to the catalyst surface, relative to $\mathrm{H}_{2} \mathrm{O}(\mathrm{g})$ and $\mathrm{H}_{2}(\mathrm{~g})$ at $\mathrm{U}=0 \mathrm{~V}$ and standard conditions ( $\mathrm{T}=298.15 \mathrm{~K}, \mathrm{P}=1 \mathrm{bar}$, and $\mathrm{pH}=0$ ) (See Supporting Information). The difference between the equilibrium potential of $U=1.23 \mathrm{~V}$ and the limiting potential is referred as the theoretical overpotential $(\eta)$, i.e. $\eta=1.23 \mathrm{~V}-\mathrm{UL}$. Lower $\eta$ or higher UL indicate improved theoretical ORR activity. It is important to note that $\eta$ should not be compared directly with a measured overpotential, since the measured overpotentials depend on the current density. ${ }^{5}$

\subsection{Materials}

Used as received unless otherwise noted: antimony chloride (Alfa Aesar, 99.9\%), manganese nitrate tetrahydrate (Sigma Aldrich, $\geq 97.0 \%$ ), cobalt nitrate hexahydrate (Sigma Aldrich, $\geq 98 \%$ ), nickel nitrate hexahydrate (Sigma Aldrich, $99.999 \%$ trace metals basis), iron nitrate nonahydrate (Sigma Aldrich, 99.99\% trace metals basis), ethanol (Sigma Aldrich, anhydrous $\geq 99.5 \%$ ), ethylenediamine (Sigma Aldrich, 99+\%), boron nitride (Alfa Aesar, 99.5\% metals basis), potassium hydroxide (Fisher Chemical, 86.4\% assay), perchloric acid (Honeywell Fluka, 70\%), glassy carbon electrodes (Pine Research Instrument, $0.196 \mathrm{~cm}^{2}$ geometrical area, polished), graphite counter electrode, and $\mathrm{Ag} / \mathrm{AgCl}$ reference electrode (Fisherbrand, Accumet).

\subsection{Synthesis}

The antimonate catalysts were synthesized using a colloidal synthesis method, as reported in the literature. ${ }^{29}$ Antimony chloride and ethylenediamine are air and moisture sensitive and must be handled in inert atmosphere in a glovebox. Briefly, $5 \mathrm{mmol}$ of transition metal nitrate $(\mathrm{s})$ and $10 \mathrm{mmol}(2.28 \mathrm{~g})$ antimony chloride $\left(\mathrm{SbCl}_{3}\right)$ were dissolved in ethanol. $0.5 \mathrm{~mL}$ of ethylenediamine was dissolved in ethanol and then added to the transition metal nitrate- $\mathrm{SbCl}_{3}$ mixture. The mixture was stirred for $24 \mathrm{~h}$ then transferred to a furnace boat and dried for $8 \mathrm{~h}$ at $200{ }^{\circ} \mathrm{C}$. The resulting powder was ground and then calcined for $5 \mathrm{~h}$ at $800^{\circ} \mathrm{C}$ to produce the antimonate.

\subsection{Physical Characterization}

X-ray photoelectron spectroscopy (XPS) was performed using a Phi Versaprobe 3 with monochromatized Al Ka $(1486 \mathrm{eV})$ radiation. The spectra were calibrated to the 
adventitious $\mathrm{C}$ 1s peak at $284.8 \mathrm{eV}$. Using CasaXPS software, peak fitting was performed with Shirley backgrounds and Gaussian-Lorentzian line shapes. Powder $\mathrm{x}$-ray diffraction (PXRD) data were obtained using a D8 Venture single crystal diffractometer (Bruker, $\lambda=1.5418 \AA$ ). Transmission electron microscopy (TEM) experiments were carried out in a FEI Titan 80-300 kV Environmental TEM operated at $300 \mathrm{kV}$. The TEM was equipped with an image corrector which allows $0.07 \mathrm{~nm}$ resolution for high resolution TEM imaging. Selected area diffraction patterns were taken using the same machine and were calibrated using a standard Si [110] diffraction pattern. Scanning transmission electron microscopy with energy dispersive x-ray spectroscopy (STEM-EDS) and STEM annular dark field (STEM-ADF) was performed with a probe size of $0.3 \mathrm{~nm}$ to map elemental composition of the catalysts. The STEM-ADF images were taken with convergence angles of 19-25 mrad. Soft x-ray absorption spectroscopy (XAS) data for O K-edge and $\mathrm{Mn}, \mathrm{Fe}, \mathrm{Co}$, and Ni L-edges were collected at the Stanford Synchrotron Radiation Light Source (SSRL) on BL 8-2 in total electron yield (TEY) mode, with a probe depth of $10 \mathrm{~nm}$.

The collected data were normalized to the $L_{2}$ edge jump after subtraction of the pre-edge region with the Athena and Larch softwares. ${ }^{30,31} \mathrm{MnO}_{2}, \mathrm{Mn}_{2} \mathrm{O}_{3}, \mathrm{Mn}$ foil, $\mathrm{Fe}(\mathrm{III}) \mathrm{O}_{x}$, Fe foil, $\mathrm{CoO}$, Co foil, $\mathrm{NiO}, \mathrm{Ni}$ foil, $\mathrm{Sb}_{2} \mathrm{O}_{4}$, and antimony-doped tin oxide (ATO, $\mathrm{Sb}_{2} \mathrm{O}_{5}$ ) were used as standards. Sb $L_{3}$ and $L_{1}$ edges at $4130 \mathrm{eV}$ and $4700 \mathrm{eV}$, respectively, were collected on BL 4-1 at SSRL in transmission mode under He atmosphere to avoid the $\mathrm{x}$-ray attenuation from air, while $\mathrm{Mn} \mathrm{K}$-edge at $6540 \mathrm{eV}$ was measured on the same beamline with similar configuration. $\mathrm{Sb}_{2} \mathrm{O}_{4}, \mathrm{ATO}, \mathrm{MnO}_{2}, \mathrm{Mn}_{3} \mathrm{O}_{4}$, and $\mathrm{Mn}_{2} \mathrm{O}_{3}$ were used as standards. The data were normalized by the edge-jump after subtraction of a linear preedge with the Athena and Larch softwares. ${ }^{30,31} \mathrm{~N}_{2}$ physisorption (BET) experiments were carried out on a Micromeritics 3Flex instrument. The samples were degassed under vacuum at $250{ }^{\circ} \mathrm{C}$ for $12 \mathrm{~h}$ prior to $\mathrm{N}_{2}$ adsorption at liquid nitrogen temperature. X-ray fluorescence (XRF) measurements were conducted in a Spectro Xepos HE XRF Spectrometer.

\subsection{Electrochemical Characterization}

Electrochemical measurements were conducted using a rotating disk electrode (RDE) in $0.1 \mathrm{M} \mathrm{KOH}$ electrolyte purged with $\mathrm{O}_{2}$ or $\mathrm{N}_{2}$ with a graphite counter electrode. Selectivity for the $2 \mathrm{e}^{-}$versus $4 \mathrm{e}^{-}$ORR was measured using a rotating ring disk electrode (RRDE) with a Au ring collection efficiency of $21 \%$, as calibrated using the $\mathrm{Fe}(\mathrm{CN})_{6}{ }^{3-} \mathrm{Fe}(\mathrm{CN}) 6^{4-}$ redox couple. The $\mathrm{Ag} / \mathrm{AgCl}$ reference electrode was calibrated using a reversible hydrogen electrode. The iR losses were compensated during the measurement at $85 \%$, using the series resistance of the cell measured at $100 \mathrm{kHz}$. Electrochemical activity was measured using cyclic voltammetry employing a Biologic VSP-300 Potentiostat. All voltammograms were corrected for background current by subtracting the $\mathrm{N}_{2}$ baseline. The working electrodes were prepared by drop casting the catalyst inks onto the glassy 
carbon electrodes for a catalyst mass loading of $0.25 \mathrm{mg} \mathrm{cm}^{-2}$ geo and catalyst to carbon ratio of $4: 1$. A typical ink composition consisted of $2.0 \mathrm{mg}$ of catalyst sonicated in $0.3 \mathrm{~mL}$ of IPA with $6 \mu \mathrm{L}$ of Nafion with $0.5 \mathrm{mg}$ of vulcan $\mathrm{C}$.

\section{Results and Discussion}

\subsection{Theoretical Insights on First-row Transition Metal Antimonates}

DFT calculations were performed following the systematic theoretical framework developed in our previous study ${ }^{21}$ to investigate the ORR catalytic activity of the first-row transition metal antimonates, $\mathrm{MSb}_{2} \mathrm{O}_{6}$, where $\mathrm{M}=\mathrm{Mn}, \mathrm{Fe}, \mathrm{Co}$, and $\mathrm{Ni}$. In the first step, we gathered the tetragonal antimonate structures with the $P 42 / m n m$ [136] space group (Figure 1A) from the Materials Project (MP) database ${ }^{25}$ and optimized the bulk structures (Figure S1). It is important to note that $\mathrm{FeSb}_{2} \mathrm{O}_{6}, \mathrm{CoSb}_{2} \mathrm{O}_{6}$, and $\mathrm{NiSb}_{2} \mathrm{O}_{6}$ only exist in $\mathrm{P}_{2} / \mathrm{mnm}$ [136] space group, while there are multiple possible space groups for $\mathrm{MnSb}_{2} \mathrm{O}_{6}$. Among the $P 321$ [150], $P \overline{3} 1 \mathrm{~m}$ [162], $P 4_{2} / \mathrm{mnm}$ [136] and $C 2 / m$ [12] space groups available for $\mathrm{MnSb}_{2} \mathrm{O}_{6}$, the $\mathrm{P}_{2} / \mathrm{mnm}$ [136] bulk unit cell was selected for consistency with the experimentally observed structure (see Section 3.2). The band gap calculated using the HSE functional for $\mathrm{MnSb}_{2} \mathrm{O}_{6}, \mathrm{FeSb}_{2} \mathrm{O}_{6}, \mathrm{CoSb}_{2} \mathrm{O}_{6}$, and $\mathrm{NiSb}_{2} \mathrm{O}_{6}$ with the $\mathrm{P}_{2} / \mathrm{mnm}$ [136] space group are $0,0,0.92$, and $1.33 \mathrm{eV}$, respectively. ${ }^{20}$ The metallic nature of $\mathrm{MnSb}_{2} \mathrm{O}_{6}$ and $\mathrm{FeSb}_{2} \mathrm{O}_{6}$ and the relatively low band gap of $\mathrm{CoSb}_{2} \mathrm{O}_{6}$ and $\mathrm{NiSb}_{2} \mathrm{O}_{6}$ suggests promising electrical conductivity of first-row transition metal antimonates. In addition to the first-row transition metal antimonates, we further selected $\mathrm{Sb}_{2} \mathrm{O}_{5}$ with a space group of $C 2 / c$ [15] and $\mathrm{Sb}_{2} \mathrm{O}_{4}$ with a space group of $\mathrm{Pna2}_{1}$ [33] for our theoretical study. Next, surface structures that fulfill stoichiometry from their respective optimized bulk structure were generated up to a maximum Miller index of 1, resulting in (100), (110), (001), and (101) surfaces for the first-row transition metal antimonates (Figure 1A, S2). Pymatgen generated multiple surfaces with different $\mathrm{O}$-atom terminations for a given Miller index, and the surface with the lowest energy was selected for activity studies. For the tetragonal antimonates, the Miller index with the lowest surface energy was the (110) surface, followed by the (100), (101), and (001) surfaces, respectively. The lowest surface energy for the (110) surface agrees well with the experimentally determined strongest diffraction peak for the (110) surface from x-ray diffraction (XRD) patterns for tetragonal crystal systems with the $P 4_{2} / m n m$ [136] space group (see Section 3.2). As the coverage of reaction intermediates could significantly impact the local environment of the active site, ${ }^{32}$ it is important to determine the most relevant surface coverage under the ORR reaction conditions to calculate the electrocatalytic activity. Therefore, surface Pourbaix diagrams ${ }^{33}$ were constructed at three extreme coverages - pristine $\left(^{*}\right), \mathrm{OH}^{*}$-terminated, and $\mathrm{O}^{*}$-terminated (Figure S3). The surface coverage at the ORR-relevant potential of $0.8 \mathrm{~V}$ vs RHE were selected for further activity calculations. Finally, we proceeded to 
calculate the energetics of all the ORR reaction intermediates $\left(\mathrm{OOH}^{*}, \mathrm{O}^{*}\right.$, and $\left.\mathrm{OH}^{*}\right)$ and determined the theoretical activity for antimonates surface facets.

The calculated ORR activities (Figure 1B) of first row antimonates are plotted against the $\triangle \mathrm{GoH}_{\mathrm{O}}$ descriptor using the $4 \mathrm{e}^{-}$ORR kinetic volcano based on the microkinetic model recently developed for oxides. ${ }^{14}$ Additionally, linear scaling relations for ORR intermediates and a two-dimensional volcano plot, which indicates the theoretical ORR overpotential, noRR, using $\Delta \mathrm{GoOH}^{*}$ and $\Delta \mathrm{GoH}^{*}$ descriptor energies, are shown in Figure S4 and Figure S5, respectively. Based on the scaling relations, we observe that almost all of the oxide surfaces considered in this study follow a linear scaling relation of $\Delta \mathrm{GoOH}^{*}$ $=\Delta \mathrm{GOH}^{*}+3.2 \mathrm{eV}$ (Figure S4A), indicating the universal nature of bonding between $\mathrm{OH}^{*}$ and $\mathrm{OOH}^{\star}{ }^{21,34}$. We further observe that most of the ORR reaction intermediates adsorb weakly on the oxide surfaces (Figure S4), placing these catalysts on the weak adsorption region of the ORR activity volcano. Unlike transition metals where the $\mathrm{O}^{*}$ intermediate adsorbs strongly on hollow sites, on oxides, $\mathrm{O}^{*}$ adsorbs weakly at top sites. ${ }^{14}$ This weak adsorption of $\mathrm{O}^{*}$ at the top sites of oxide surfaces shows a significant response to the electric field and results in upshift of the right leg of the volcano and significantly higher activity on oxide surfaces at a higher $\mathrm{pH}$ compared to a lower $\mathrm{pH}$ (Figure 1B). ${ }^{14}$ Based on the $4 \mathrm{e}^{-}$ORR kinetic volcano, $\mathrm{MnSb}_{2} \mathrm{O}_{6}$ shows the highest theoretical activity followed, in descending order, by $\mathrm{CoSb}_{2} \mathrm{O}_{6}, \mathrm{NiSb}_{2} \mathrm{O}_{6}$ and $\mathrm{FeSb}_{2} \mathrm{O}_{6}$. ORR reaction intermediates adsorb strongly on the surface $\mathrm{Sb}$ active site moieties and result in low activities, and thus the theorized active site for $\mathrm{MSb}_{2} \mathrm{O}_{6}$ is the transition metal site. Theoretical activities of all the considered antimonate surfaces are presented in the two-dimensional volcano plot in Figure S5. The calculated theoretical limiting potentials for the (110), (100), (101), and (001) surfaces on $\mathrm{MnSb}_{2} \mathrm{O}_{6}$ are $0.19,0.16,0.41$, and $0.81 \mathrm{~V}$, respectively (Figure S6). Similar trends were observed for the other antimonates, indicating that ORR activity is strongly dependent on the surface-active site moieties. Moreover, these trends highlight the importance of studying facets other than the most stable surface facet (usually determined from XRD) for a given material. Based on our theoretical ORR activity analysis, we determine that all the antimonates are sufficiently active for ORR, and in particular $\mathrm{MnSb}_{2} \mathrm{O}_{6}$ emerges as the first-row transition metal antimonate with the highest calculated ORR activity. 
A

$\mathrm{MSb}_{2} \mathrm{O}_{6}$ bulk structure

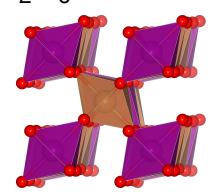

$\mathrm{MSb}_{2} \mathrm{O}_{6}$ surface structures

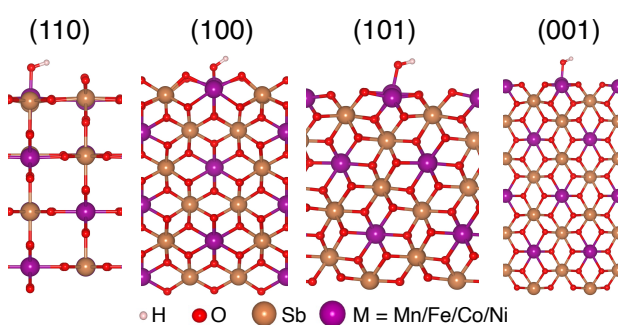

B

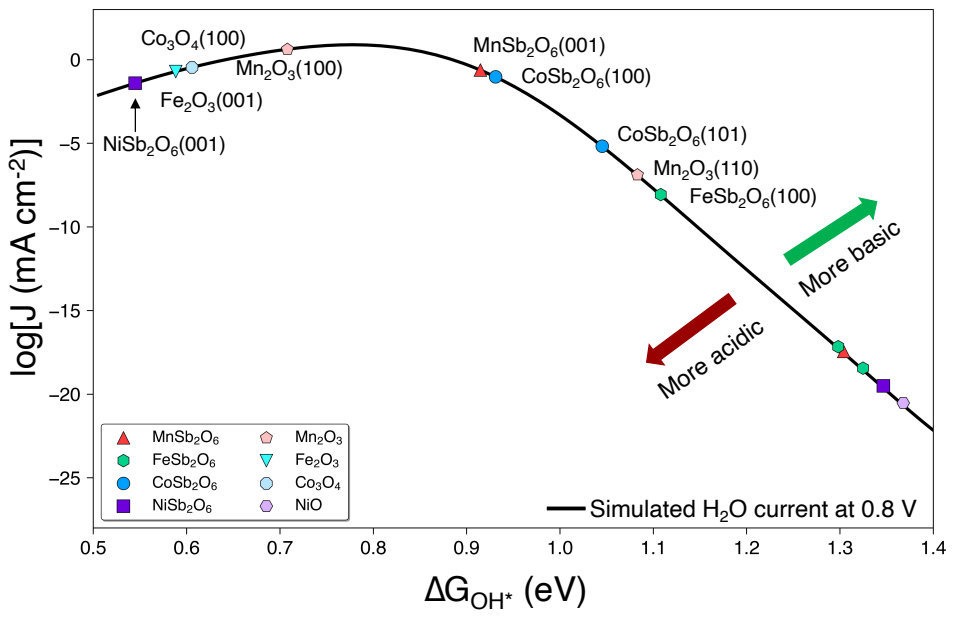

Figure 1. DFT calculated ORR activity on first-row transition metal antimonates (A) Unit cell of the bulk tetragonal $\mathrm{MSb}_{2} \mathrm{O}_{6}$ structure with the $P 4_{2} / \mathrm{mnm}$ [136] space group, where $\mathrm{M}=\mathrm{Mn}, \mathrm{Fe}, \mathrm{Co}$, and $\mathrm{Ni}$, and the considered (110), (100), (101), and (001) surface structures. The $\mathrm{OH}^{*}$ adsorption sites are indicated for clarity. (B) Calculated ORR activities of surfaces considered in this study plotted on the $4 \mathrm{e}^{-}$oxide ORR kinetic volcano at $0.8 V_{\text {RHE. }}$ Arrows indicate the shift in the right leg of the volcano due to field effects: activity increases at high $\mathrm{pH}$ and decreases at lower $\mathrm{pH}$.

Pure transition metal oxides of $\mathrm{Mn}, \mathrm{Co}, \mathrm{Fe}$, and $\mathrm{Ni}$ have been extensively studied for the ORR. ${ }^{7}$ Among these oxides, $\mathrm{MnO}_{x}$ are well known alkaline ORR electrocatalysts. ${ }^{11,12} \mathrm{Mn}$ can exist in several different oxidation states $(+2,+2.67,+3$, and +4$)$, depending on the crystal structure. Though the ORR activity of $\mathrm{MnO}_{x}$ depends on a variety of factors including chemical composition, crystallographic phase, oxidation state, morphology and surface area, it has been shown that the ORR activity of different $\mathrm{MnO}_{x}$ materials typically increases in the order of $\mathrm{MnO}<\mathrm{Mn}_{5} \mathrm{O}_{8}<\mathrm{Mn}_{3} \mathrm{O}_{4}<\mathrm{Mn}_{2} \mathrm{O}_{3}$ and the activity of $\mathrm{MnO}_{2}$ strongly depends on its crystallographic phase. ${ }^{7}$ Among these materials, $\mathrm{Mn}_{3} \mathrm{O}_{4}$ and $\mathrm{Mn}_{2} \mathrm{O}_{3}$ are widely studied due to their considerable ORR activities. Based on a combined experimental and theoretical study, Su et al. ${ }^{11}$ demonstrated $\mathrm{Mn}_{2} \mathrm{O}_{3}(110)$ as the active surface for alkaline ORR. The spinel-type $\mathrm{CO}_{3} \mathrm{O}_{4}$, which has $\mathrm{Co}$ with +2 and +3 oxidation states occupying its tetrahedral and octahedral sites, respectively, is the most employed catalyst for ORR compared to other cobalt oxides such as CoO. ${ }^{30}$ The surface structure of $\mathrm{Co}_{3} \mathrm{O}_{4}$ can also affect its ORR catalytic activity, which is attributed to the density of $\mathrm{Co}^{2+}$ content. ${ }^{13}$ Pure oxides of $\mathrm{Ni}$ and $\mathrm{Fe}$ have also been confirmed to be active towards ORR but to a lesser extent than $\mathrm{MnO}_{\mathrm{x} .}{ }^{8}$ 
The calculated activities of pure oxides are plotted on the $4 \mathrm{e}^{-}$ORR kinetic volcano (Figure 1B). Furthermore, Figure $\mathbf{S 6}$ summarizes the calculated limiting potentials for the antimonates and corresponding pure oxides. A more positive limiting potential indicates a higher activity and is therefore desirable for catalysis on cathodes in fuel cells. $\mathrm{Mn}_{2} \mathrm{O}_{3}$ demonstrates a high theoretical activity towards ORR in agreement with the experimental literature. ${ }^{11}$ Interestingly, the theoretical activity of $\mathrm{MnSb}_{2} \mathrm{O}_{6}(001)$ surface is higher than the previously studied $\mathrm{Mn}_{2} \mathrm{O}_{3}(110)$ surface. Similar to $\mathrm{MnSb}_{2} \mathrm{O}_{6}$, the rest of the first-row transition metal antimonates show higher intrinsic activity compared to their corresponding oxide surface (Figure 1B and Figure S6). Based on our DFT results, we identify that all the antimonates are sufficiently active for ORR, and in particular $\mathrm{MnSb}_{2} \mathrm{O}_{6}$ emerges as the first-row transition metal antimonate with the highest ORR activity.

\subsection{Materials Characterization of Transition Metal Antimonates}

As discussed in the previous section, theoretical studies predict that transition metal (where $\mathrm{M}=\mathrm{Mn}, \mathrm{Fe}, \mathrm{Co}, \mathrm{Ni}$ ) antimonate catalysts are active for the ORR. Furthermore, this class of materials shows particular promise for enhancing metal oxide performance by tuning metal active sites and increasing activity on a per-metal site basis. Experimental validation of these predictions is important both to benchmark the computational techniques and to understand the ORR performance of these previously unexplored materials. $\mathrm{Mn}$ and $\mathrm{Ni}$ antimonates have previously been studied in the thin film morphology for the OER, ${ }^{17-19}$ demonstrating conductivity and substantial stability. However, utilization of thin film oxides for the ORR is more complex because of the incompatibility of the standard glassy carbon disk substrate with the high temperature oxidation process needed to produce the transition metal antimonate film. ${ }^{35}$ For this reason, the materials were synthesized in a nanoparticle morphology and subsequently deposited on the glassy carbon substrate with a conductive carbon support. For nanoparticulate synthesis, the metal nitrate precursor was added to a mixture of antimony chloride and ethylenediamine dissolved in ethanol and subsequently mixed for $24 \mathrm{~h}$ at room temperature under air. ${ }^{29}$ The resulting product was dried and then calcined at $800^{\circ} \mathrm{C}$ for $5 \mathrm{~h}$ under static air to produce the final crystalline transition metal antimonate.

As shown by the theoretical investigation, the material properties and ORR activity of the catalyst are highly dependent on the crystal surface structure (Figure S6). Figure 2A shows the powder XRD measurements of the 4 catalysts and reference structures. The strongest peaks for all the materials are at $\sim 27.1^{\circ}, 35.1^{\circ}$, and $53.2^{\circ}$, corresponding to the (110), (101), and (211) planes of the rutile $\mathrm{MSb}_{2} \mathrm{O}_{6}$ structure with space group $\mathrm{P} 42 / \mathrm{mnm}$ [136]. There are also some low intensity peaks corresponding to $\mathrm{MnSb}_{2} \mathrm{O}_{4}$ (space group $P 4_{2} / m b c$ [135]) in the Mn diffractogram and $\mathrm{Sb}_{2} \mathrm{O}_{4}$ (space group Pna2 ${ }_{1}$ [33]) in all of the synthesized catalysts. For simplicity, the $\mathrm{Mn}$ antimonate will be referred to as $\mathrm{MnSb}_{2} \mathrm{O}_{6}$, corresponding to the dominant crystal phase. Diffractograms for the transition metal 
oxides synthesized under analogous conditions (but without the Sb precursor) are shown in Figure S7. While XRD gives bulk structural information, TEM can be used to further understand the local variations in particle size, shape, and crystal structure. Previous studies have found that surface area and exposed facets of the nanoparticles have the largest effect on activity, ${ }^{36}$ and therefore we focus on these properties of the materials to best compare them. TEM images in Figure 2B and Figure $\mathbf{S 8}$ show that the particles are typically ovoid in shape, with dimensions below $40 \mathrm{~nm}$. $\mathrm{CoSb}_{2} \mathrm{O}_{6}$ is an exception with rectangular particles reaching up to $100 \mathrm{~nm}$ in length. Overall, the particles are heterogeneous in size, shape, and agglomeration, so BET measurements were used to determine the surface area (without carbon). The measured BET surface areas, which range from $2.57 \mathrm{~m}^{2} \mathrm{~g}^{-1}$ for $\mathrm{CoSb}_{2} \mathrm{O}_{6}$ to $8.36 \mathrm{~m}^{2} \mathrm{~g}^{-1}$ for $\mathrm{NiSb}_{2} \mathrm{O}_{6}$, are reported in Table 1. Beyond morphology, selected area diffraction patterns (SADPs) and fast Fourier transform (FFT) analysis of high resolution (HR)-TEM images were used to probe the crystal structure, crystallinity, and faceting. The particles are highly crystalline and the rings in the SADP match well with the results observed by XRD (Figure 2, Table S1). FFT analysis shows the $d$ spacings and angles between planes for the individual particles (Figure S8), further confirming the majority rutile structure for all catalysts.

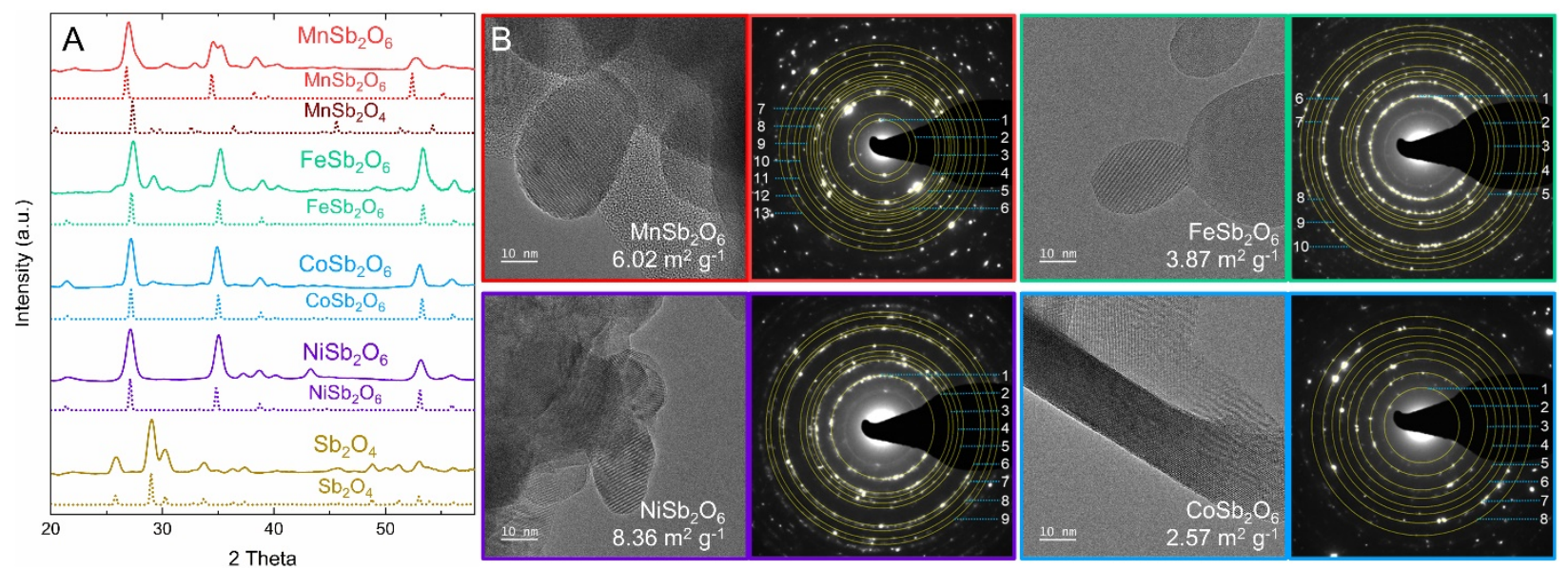

Figure 2. Structural and Morphological Characterization of the Antimonates Structural characterization of the antimonate catalysts: $\mathrm{MnSb}_{2} \mathrm{O}_{6}$ (red), $\mathrm{FeSb}_{2} \mathrm{O}_{6}$ (green), $\mathrm{CoSb}_{2} \mathrm{O}_{6}$ (blue), $\mathrm{NiSb}_{2} \mathrm{O}_{6}$ (purple), and $\mathrm{Sb}_{2} \mathrm{O}_{4}$ (gold). (A) XRD diffractograms with reference structures: $\mathrm{MnSb}_{2} \mathrm{O}_{6}$ (red, ICSD 74380), $\mathrm{MnSb}_{2} \mathrm{O}_{4}$ (dark red, ICSD 243444), $\mathrm{FeSb}_{2} \mathrm{O}_{6}$ (green, ICSD 40344). $\mathrm{CoSb}_{2} \mathrm{O}_{6}$ (blue, ICSD 203094), $\mathrm{NiSb}_{2} \mathrm{O}_{6}$ (purple, ICSD 426852), and $\mathrm{Sb}_{2} \mathrm{O}_{4}$ (gold, ICSD 153154). ${ }^{37}$ (B) TEM images and SADP analysis of crystallites. Clockwise from top left: $\mathrm{MnSb}_{2} \mathrm{O}_{6}, \mathrm{FeSb}_{2} \mathrm{O}_{6}, \mathrm{CoSb}_{2} \mathrm{O}_{6}$, and $\mathrm{NiSb}_{2} \mathrm{O}_{6}$. BET surface areas are included for reference. List of $d$-spacings and planes from the SADPs can be found in the Table $\mathbf{S 1 .}$ 
In addition to the physical properties of the material, it is also important to understand the composition, oxidation state, and geometry of the active site, particularly as these compare to the pure metal oxides. The quantitative compositions of the powders were determined by XRF and are listed in Table 1. The transition metal percentage of the total metal for the antimonates was $\sim 30-45 \%$, comparing well with the expected $33 \%$ for the $\mathrm{MSb}_{2} \mathrm{O}_{6}$ structure. Although analysis is complicated by the overlap between the $\mathrm{Sb} 3 \mathrm{~d}$ and $\mathrm{O}$ 1s spectra (Figure S9), the approximate elemental composition calculated from XPS spectra is in agreement with the XRF within the errors of each technique (Table 1). The oxidation state of $\mathrm{Sb}$ in each compound was determined by fitting the $\mathrm{Sb} 3 \mathrm{~d}_{3 / 2}$ spectrum, which has no overlap with the $O 1$ s signal. The antimonates have primarily $\mathrm{Sb}^{5+}$ character, with the $\mathrm{Sb} 3 \mathrm{~d}_{3 / 2}$ peak centered at $\sim 540.3 \mathrm{eV}$, as is expected for the rutile structure (Figure S9). ${ }^{38} \mathrm{NiSb}_{2} \mathrm{O}_{6}$ and $\mathrm{FeSb}_{2} \mathrm{O}_{6}$ also have small $\mathrm{Sb}^{3+}$ contributions, with an additional peak at $\sim 539.3 \mathrm{eV}$, corresponding to average $\mathrm{Sb}$ oxidation state of 4.8 and 4.33 , respectively.

Table 1. Summary of Characterization for Antimonates and Oxides

\begin{tabular}{|c|c|c|c|c|c|c|c|}
\hline Catalyst & $\begin{array}{c}\text { Particle } \\
\text { Shape }\end{array}$ & $\begin{array}{c}\text { BET } \\
\text { Surface } \\
\text { Area } \\
\left(\mathbf{m}^{2} / \mathbf{g}\right)\end{array}$ & $\begin{array}{c}\text { \% TM } \\
\text { (expected) }\end{array}$ & $\begin{array}{c}\text { \% TM } \\
\text { (XRF) }\end{array}$ & $\begin{array}{c}\text { \% TM } \\
\text { (XPS) }\end{array}$ & \% Sb S+ $^{5+}$ & $\begin{array}{c}\text { TM } \\
\text { Oxidation } \\
\text { State } \\
\text { (XPS) }\end{array}$ \\
\hline $\mathrm{MnSb}_{2} \mathrm{O}_{6}$ & Ovoid & 6.02 & 33 & 38 & 44 & 100 & $2+$ \\
\hline $\mathrm{FeSb}_{2} \mathrm{O}_{6}$ & Ovoid & 3.87 & 33 & 35 & 38 & 67 & $3+$ \\
\hline $\mathrm{CoSb}_{2} \mathrm{O}_{6}$ & Rectangular & 2.57 & 33 & 28 & 38 & 100 & $2+$ \\
\hline $\mathrm{NiSb}_{2} \mathrm{O}_{6}$ & Ovoid & 8.36 & 33 & 29 & 44 & 90 & $2+$ \\
\hline
\end{tabular}

We can gain further insight into the nature of each element in the bulk of the compounds using $\mathrm{Sb}, \mathrm{Mn}, \mathrm{Fe}, \mathrm{Co}$, and $\mathrm{Ni}$ L edge x-ray absorption spectroscopy (XAS) (Figure 3). Using the shape and position of the spectra, we aim to understand the state of the transition metal in the antimonate as compared to pure oxides, as well as to understand if and how the antimony varies based on the identity of the transition metal. The $S b L_{3}$ and $L_{1}$ edges probe the $2 p_{3 / 2}$ to $5 d$ and $2 s$ to $5 p$ transitions, respectively, and have several features that can be used to identify the oxidation state and coordination environment of the $\mathrm{Sb}$ (Figure 3A, S10). In particular, the position of the $L_{1}$ absorption edge is indicative of oxidation state. ${ }^{39,40}$ The $\mathrm{L}_{1}$ spectrum for $\mathrm{Sb}_{2} \mathrm{O}_{4}$ shows two peaks, at 4702 and $4707 \mathrm{eV}$, corresponding well to the approximately $50: 50$ mixture of $\mathrm{Sb}(\mathrm{III})$ and $\mathrm{Sb}(\mathrm{V})$ expected for this structure. Comparatively, the $\mathrm{L}_{1}$ spectra for $\mathrm{Sb}_{2} \mathrm{O}_{5}$ and the antimonates show only one distinct peak at $\sim 4706 \mathrm{eV}$, indicating primary $\mathrm{Sb}(\mathrm{V})$ character for all, as was found as 
the majority oxidation state via XPS for Mn, Co, and Ni. Derivatives of the $L_{1}$ spectra show that there are two possible peaks at $\sim 4701$ and $\sim 4704 \mathrm{eV}$, corresponding to $\mathrm{Sb}$ (III) and $\mathrm{Sb}(\mathrm{V})$, respectively. ${ }^{39} \mathrm{The} \mathrm{Mn}, \mathrm{Co}$, and $\mathrm{Ni}$ antimonates show only the higher energy peak, however the $\mathrm{Fe}$ antimonate exhibits both peaks, indicating a mixture of $\mathrm{Sb}(\mathrm{III})$ and $\mathrm{Sb}(\mathrm{V})$ (Figure 3A), as supported by the XPS data showing only $\mathrm{Sb}(\mathrm{V})$ character (Figure S9). In the $L_{3}$ spectra, the position and shape of the first peak of the absorption edge, which provide a fingerprint for the $\mathrm{Sb}$ coordination environment, are highly similar with sharp, well-define peaks for the antimonates (Figure S10). This indicates a highly crystalline local environment, in contrast with the broader features and higher local disorder found in the $\mathrm{Sb}_{2} \mathrm{O}_{4}{ }^{39,41}$ We can thus conclude that the state of the $\mathrm{Sb}$ is very similar in the $\mathrm{Mn}$, $\mathrm{Co}$, and $\mathrm{Ni}$ antimonates, but shows more mixed character in the Fe antimonate.

Finally, the transition metal $\mathrm{L}_{2,3}$ edge (Figure 3B-E) and XPS $2 p$ (Figure S11) spectra allow us to compare the state of the transition metal in the antimonate versus a pure oxide. This data is discussed in more detail in the Supporting Information and the comparison is summarized in Table S2. Specifically, for XAS we can use the shapes of the spectra to probe the local geometry, while the peak positions in XPS can be used to identify the transition metal oxidation state. It should be noted that both XAS in TEY mode and XPS are sensitive to the top 5-10 nm, but although both techniques involve the $2 p$ electrons, the transitions measured are different. Thus, while the techniques are complementary, they provide different information about the material. 

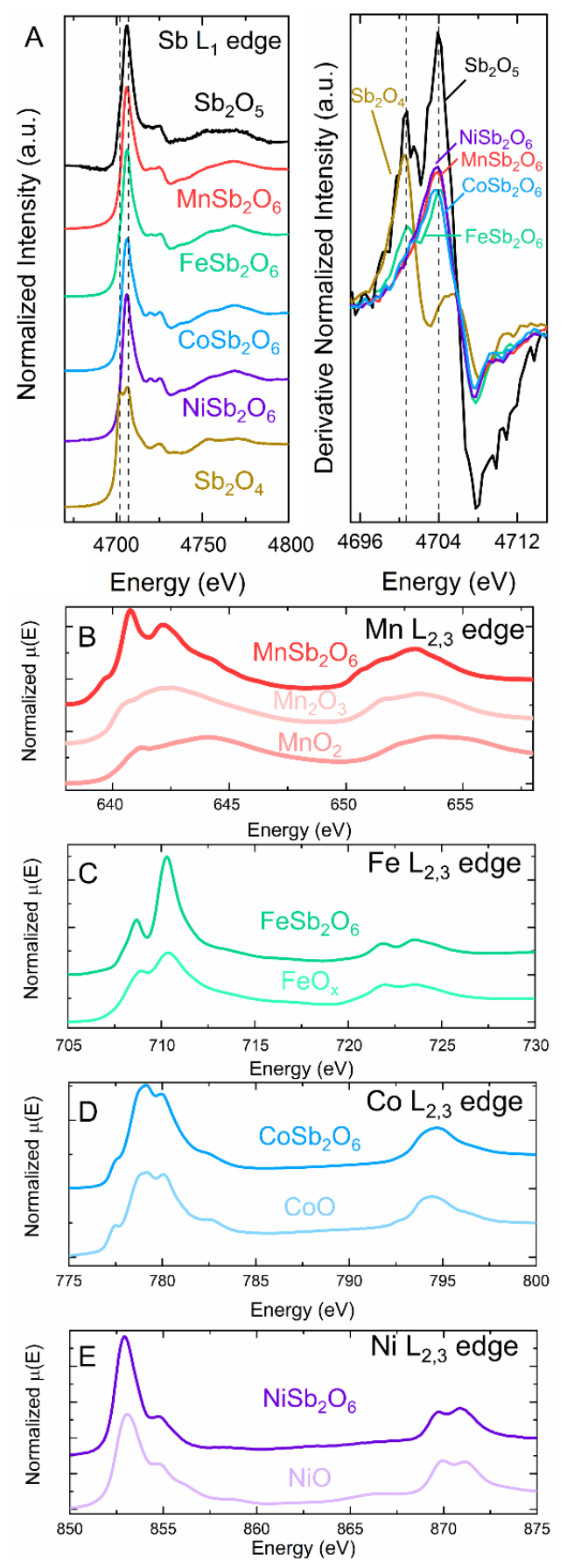

Figure 3. XAS analysis of the antimonates and oxides (A) Sb $\mathrm{L}_{1} \mathrm{XAS}$ spectra and derivatives for $\mathrm{MnSb}_{2} \mathrm{O}_{6}$ (red), $\mathrm{FeSb}_{2} \mathrm{O}_{6}$ (green), $\mathrm{CoSb}_{2} \mathrm{O}_{6}$ (blue), $\mathrm{NiSb}_{2} \mathrm{O}_{6}$ (purple), $\mathrm{Sb}_{2} \mathrm{O}_{4}$ (gold), and $\mathrm{Sb}_{2} \mathrm{O}_{5}$ (black). $\mathrm{L}_{3}$ and $\mathrm{L}_{2}$ edges of the antimonate and oxide references for (B) $\mathrm{Mn},(\mathbf{C}) \mathrm{Fe},(\mathbf{D}) \mathrm{Co}$, and (E) Ni. Dashed lines in (A) are guides to the reader, indicating the features as 4702 and $4707 \mathrm{eV}$ in the normalized Sb $\mathrm{L}_{1}$ spectra and the features at

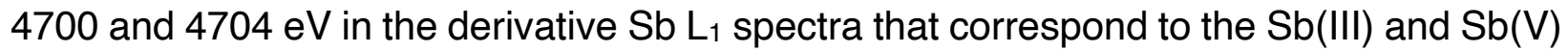
states, respectively. 
For $\mathrm{Mn}$ antimonate, the $\mathrm{Mn}$ oxidation state is determined to be $2+$ on the basis of semiempirical fitting of the Mn $2 p$ XPS spectrum to Mn(II)O (Figure S11A), as well as the positions of the pre-edge and sharp main edge features in the $M n L_{2,3}$ edge spectrum (Figure 3B). ${ }^{42}$ In agreement with XRD, the XPS spectrum for the $\mathrm{Mn}_{2} \mathrm{O}_{3}$ reference is fit to $\mathrm{Mn}^{3+}$. These conclusions are in agreement with the DFT-computed Bader charges for $\mathrm{Mn}$ in the antimonate and in the oxide (Figure S12). For both $\mathrm{Fe}$ antimonate and oxide, the Fe 2p XPS spectrum is fit to an average of Fe(III) species (Figure S11B) and the two main peaks in the $\mathrm{Fe} \mathrm{L}_{3}$ spectra correspond well to octahedral Fe ${ }^{3+}$ (Figure 3C).43,44 Taken together with the XRD pattern showing small peaks corresponding to the $\mathrm{Sb}_{2} \mathrm{O}_{4}$ structure and the average 4.33+ oxidation state of $\mathrm{Sb}$ from XPS and XAS, we conclude that the Fe sample is a mixture of the $\mathrm{Fe}(\mathrm{III}) \mathrm{Sb}(\mathrm{III} / \mathrm{V})_{2} \mathrm{O}_{6}$ and $\mathrm{Sb}(\mathrm{III} / \mathrm{V})_{2} \mathrm{O}_{4}$ structures. For the Co antimonate, the oxidation state is identified as 2+, due to fitting of the Co $2 p$ XPS to $\mathrm{Co}(\mathrm{II})(\mathrm{OH})_{2}$ (Figure S11C) and the position of the main and shoulder peaks in the Co $\mathrm{L}_{2,3}$ edge spectra, which match well with a $\mathrm{Co}$ (II)O reference and correspond to octahedral $\mathrm{Co}^{2+}$ (Figure 3D). ${ }^{45-47}$ The XPS spectrum of the synthesized oxide reference fits to a mix of tetrahedral $\mathrm{Co}^{2+}$ and octahedral $\mathrm{Co}^{3+}$ sites in $\mathrm{Co}_{3} \mathrm{O}_{4}$. Finally, the $\mathrm{Ni}_{2,3}$ edge spectra for both the $\mathrm{Ni}$ antimonate and oxide are consistent with octahedral $\mathrm{Ni}^{2+}$ sites (Figure 3E). ${ }^{48}$ While the $\mathrm{Ni} 2 \mathrm{p}$ spectrum for the oxide is fit to $\mathrm{Ni}(\mathrm{II}) \mathrm{O}$, the antimonate is best fit $\mathrm{Ni}(\mathrm{II})(\mathrm{OH})_{2}$, perhaps due to air exposure (Figure S11D).

Summarizing the oxidation states of transition metals in the antimonate structure, we have found the dominant states to be $\mathrm{Sb}(\mathrm{V}), \mathrm{Mn}(\mathrm{II}), \mathrm{Fe}(\mathrm{III}), \mathrm{Co}(\mathrm{II})$, and $\mathrm{Ni}(\mathrm{II})$. We have defined the structure, morphology, composition, and chemical nature of the active site of the four transition metal antimonates in order to understand the effect of the transition metal on the antimonates and the antimonate framework on the transition metal. These results are compiled in Table 1.

\subsection{Electrochemical Characterization}

With a clearer picture of the physical and chemical nature of the antimonate catalysts, and evidence of their close comparability with the structures predicted by theory, we probed their ORR performance to determine their material property-activity relationships. The electrochemical activity of the catalysts was studied in a three-electrode cell configuration, utilizing a rotating (ring) disk working electrode, graphite counter electrode, and $\mathrm{Ag} / \mathrm{AgCl}$ reference electrode, under alkaline conditions in $0.1 \mathrm{M} \mathrm{KOH}$. ORR performance, including activity and selectivity, was assessed using cyclic voltammetry in an RRDE for all catalysts. Unless otherwise specified, all ORR activity data is presented in triplicate (three separate samples). 
Figure 4A shows the total ORR performance of each transition metal antimonate and pure oxide in comparison with transition metal-free $\mathrm{Sb}_{2} \mathrm{O}_{4}$, glassy carbon, and vulcan carbon. In good agreement with the theoretical activity predictions, $\mathrm{MnSb}_{2} \mathrm{O}_{6}$ is found to have the highest onset potential of $0.82 \mathrm{~V}$ vs RHE at $0.1 \mathrm{~mA} \mathrm{~cm}^{-2}$ geo, while the other antimonates have similar onset potentials between 0.70 and $0.72 \mathrm{~V}$ vs RHE. The antimonates all show onsets higher than the glassy carbon, vulcan carbon, and $\mathrm{Sb}_{2} \mathrm{O}_{4}$ controls, but generally have similar cyclic voltammetry profiles compared to their respective transition metal oxides. On its own, vulcan carbon has a high BET surface area $\left(\sim 380 \mathrm{~m}^{2} \mathrm{~g}^{-1}\right)$ and demonstrates poor specific activity. To understand the role of the carbon support, the Mn antimonate and oxide catalysts were tested without the vulcan carbon. Overall, without the conductive support the performance is lower, but the trends between antimonate and oxide are maintained (Figure S13). This result, which we would expect to hold for the other catalysts considered in this work, indicates that the trends we observe are not due to the vulcan carbon. To understand if the antimonate provides an activity enhancement beyond the pure oxides, metrics for intrinsic activity must be determined. Herein, we use mass activity, based on the mass loading of the transition metal (TM; the predicted active site based on theory calculations) and specific activity, based on the total loaded real surface area of the catalyst from BET. Figure 4 shows plots of the potential versus the logarithm of the kinetic current density, normalized by the transition metal mass (Figure 4B) and the BET surface area (Figure 4C). The $\mathrm{MnSb}_{2} \mathrm{O}_{6}$ demonstrates the highest mass and specific activities, with $29.6 \mathrm{~A} \mathrm{~g}^{-1} \mathrm{TM}$ and $0.068 \mathrm{~mA}$ $\mathrm{cm}^{-2} \mathrm{BET}$ at $0.7 \mathrm{~V}$ vs RHE, compared to $8.4 \mathrm{~A} \mathrm{~g} \mathrm{~g}^{-1} \mathrm{TM}$ and $0.003 \mathrm{~mA} \mathrm{~cm}^{-2} \mathrm{BET}$ for the $\mathrm{Mn}_{2} \mathrm{O}_{3}$ synthesized in this study (Figure 4D). Some literature manganese oxides show higher activity than the $\mathrm{Mn}_{2} \mathrm{O}_{3}$ in this work, such as an $\alpha-\mathrm{MnO}_{2}$ that demonstrated $\sim 10 \mathrm{~A} \mathrm{~g}^{-1} \mathrm{MnO} 2$ at $0.8 \mathrm{~V}$ vs $\mathrm{RHE},{ }^{49}$ however there is significant variation in manganese oxide performance based on the exact structure, oxidation state, and surface facets. ${ }^{7,11,12}$ The enhancement is significant because previous literature has shown ORR activity to increase with increasing oxidation state of $\mathrm{Mn} ;{ }^{7}$ this indicates that the antimonate framework creates and stabilizes favorable $\mathrm{Mn}^{2+}$ active sites. Notably, the antimonates all have higher mass and specific activities than their respective oxides, with $\mathrm{Co}$ and $\mathrm{Fe}$ demonstrating significant enhancements on mass and specific activity bases, respectively. Despite their high onset potentials, in the kinetically-limited regime both $\mathrm{Mn}$ antimonate and oxide have large Tafel slopes of 130 and $170 \mathrm{mV} /$ decade, respectively (Figure S14). In contrast, the other oxides and antimonates have similar Tafel slopes of $50-70 \mathrm{mV}$, which could suggest that they have similar active sites. This is particularly interesting in the case of Co, since the Co sites are different between the oxide (octahedral $\mathrm{Co}^{2+}$ and tetrahedral $\mathrm{Co}^{3+}$ ) and the antimonate ( $\mathrm{Co}^{2+}$ only). This is in agreement with literature findings of increased ORR activity of Co oxide with increasing 2+ character, indicating that it is the dominant active site in the oxide. ${ }^{13}$ Overall, we can conclude that, in agreement with theoretical 
predictions, $\mathrm{MnSb}_{2} \mathrm{O}_{6}$ is the most active of the mixed metal oxides. Furthermore, the high mass and specific activity of $\mathrm{MnSb}_{2} \mathrm{O}_{6}$ relative to the $\mathrm{Sb}$-free $\mathrm{Mn}_{2} \mathrm{O}_{3}$ indicates that the addition of antimony increased the per-site activity of $\mathrm{Mn}$, showing that the antimony oxide framework has promise for improving transition metal site utilization.
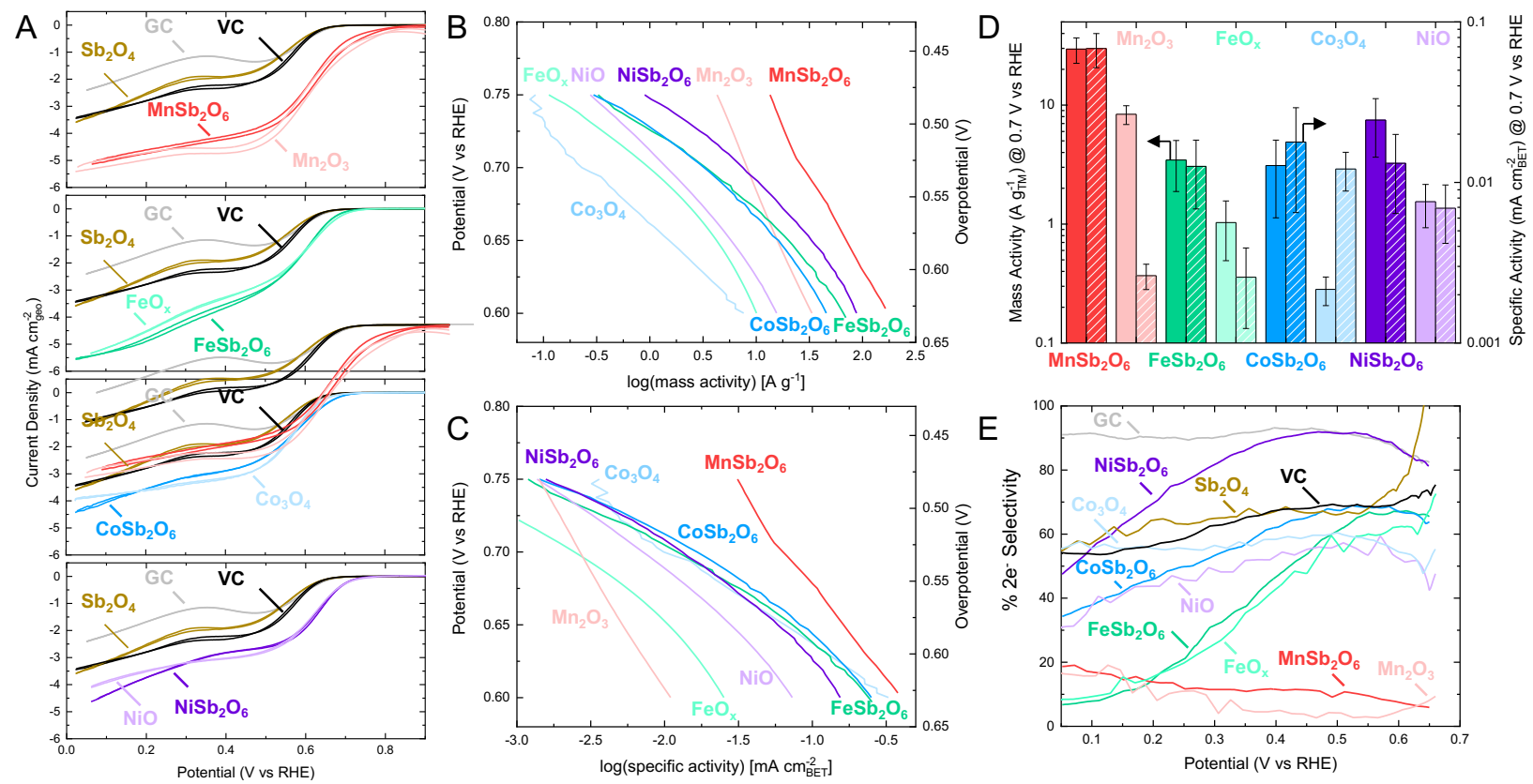

Figure 4. ORR Performance of the Transition Metal Antimonates and Oxides (A) Stacked ORR cyclic voltammetry plots comparing vulcan carbon (VC, black), glassy carbon (GC, gray), and $\mathrm{Sb}_{2} \mathrm{O}_{4}$ (gold) to $\mathrm{MnSb}_{2} \mathrm{O}_{6}$ (red) and $\mathrm{Mn}_{2} \mathrm{O}_{3}$ (pink), $\mathrm{FeSb}_{2} \mathrm{O}_{6}$ (dark green) and $\mathrm{FeO}_{x}$ (light green), $\mathrm{CoSb}_{2} \mathrm{O}_{6}$ (blue) and $\mathrm{Co}_{3} \mathrm{O}_{4}$ (light blue), and $\mathrm{NiSb}_{2} \mathrm{O}_{6}$ (dark purple) and $\mathrm{NiO}$ (light purple) in $0.1 \mathrm{M} \mathrm{KOH}$ at $1600 \mathrm{rpm}$. All data are $\mathrm{N}_{2}$-subtracted; vulcan carbon, glassy carbon, $\mathrm{Sb}_{2} \mathrm{O}_{4}$, and $\mathrm{Co}_{3} \mathrm{O}_{4}$ are reported in triplicate, while all other oxides and antimonates are reported in quadruplicate. Plots of potential versus the logarithm of the (B) mass activity (kinetic current density normalized by transition metal mass loading) and (C) specific activity (kinetic current density normalized by BET surface area) with (D) corresponding mass and specific activities for each catalyst at $0.7 \mathrm{~V}$ vs RHE. (E) Plot of $2 \mathrm{e}^{-}$selectivity versus potential calculated from the RRDE measurements.

In addition to determining the overall ORR activity, it is important to understand the selectivity of each catalyst to $4 e^{-}$vs $2 e^{-}$ORR. The $2 e^{-}$selectivity calculated from RRDE measurements is shown in Figure 4E. $\mathrm{MnSb}_{2} \mathrm{O}_{6}$ and $\mathrm{Mn}_{2} \mathrm{O}_{3}$ are observed to have low overall $2 \mathrm{e}^{-}$selectivities at all potentials, whereas $\mathrm{FeSb}_{2} \mathrm{O}_{6}, \mathrm{FeO}_{x}$, and $\mathrm{CoSb}_{2} \mathrm{O}_{6}$ all show decreasing $2 \mathrm{e}^{-}$selectivity with increasing overpotential. $\mathrm{NiSb}_{2} \mathrm{O}_{6}$ alone shows significantly different selectivity from its corresponding oxide, with significant $2 e^{-}$ 
selectivity, ranging between that of glassy carbon ( $\sim 90 \%)$ and vulcan carbon or $\mathrm{Sb}_{2} \mathrm{O}_{4}$ ( $60 \%)$. The substantial $2 \mathrm{e}^{-}$selectivity and current density for $\mathrm{NiSb}_{2} \mathrm{O}_{6}$ at $0.6 \mathrm{~V}$ vs $\mathrm{RHE}$ of $90 \%$ and $0.8 \mathrm{~mA} \mathrm{~cm}^{-2}$ geo, respectively, are comparable with the highest performing metal oxide catalyst in alkaline electrolyte. ${ }^{50-52}$ Thus, although the overall polarization curves are similar, the differences in selectivity and in Tafel slope (60 and $75 \mathrm{mV} /$ decade for $\mathrm{Ni}$ antimonate and oxide, respectively) indicate that there are mechanistic differences between the two catalysts due to the antimonate framework.

In summary, we observe enhancements in mass and specific activities for the transition metal oxides in the antimonate framework. Furthermore, for Ni specifically there also appears to be a significant difference in catalytic mechanism and $2 \mathrm{e}^{-}$selectivity in the antimony framework. Overall, we find that the antimonates are active for ORR and that $\mathrm{MnSb}_{2} \mathrm{O}_{6}$ is the most promising catalyst. This electrochemical evaluation is consistent with theoretical predictions and highlights the exciting possibilities for tuning activity and selectivity with mixed metal oxides. The role of the antimony framework in the stability of the catalysts will be discussed in the following section.

\subsection{Electrochemical and Material Stability}

The antimonate framework was identified as promising in part due to its predicted and experimentally observed stability, including in the highly oxidizing and corrosive conditions of acid OER. ${ }^{17-19}$ Pourbaix diagrams are an invaluable tool for exploring the corrosion profiles of materials as these diagrams show the most stable species as a function of $\mathrm{pH}$ and applied electrochemical potential. Therefore, we constructed Pourbaix diagrams (Figure 5) using DFT as implemented in Pymatgen ${ }^{26,53}$ to investigate the aqueous stability of the first-row transition metal antimonates under relevant ORR conditions. In addition to the Pourbaix diagrams, we also plotted the most stable phases based on the decomposition free energy $\left(\Delta G_{p b x}\right)$ of the first-row transition metal antimonates at $\mathrm{pH}=13$. Based on this analysis we determined that $\mathrm{MnSb}_{2} \mathrm{O}_{6}$ is stable from $0.35-1.39 \mathrm{~V}$ vs $\mathrm{RHE}, \mathrm{FeSb}_{2} \mathrm{O}_{6}$ is stable from $0.37-1.11 \mathrm{~V}$ vs $\mathrm{RHE}, \mathrm{CoSb}_{2} \mathrm{O}_{6}$ is stable above $0.45 \mathrm{~V}$ vs $\mathrm{RHE}$, and $\mathrm{NiSb}_{2} \mathrm{O}_{6}$ is stable above $0.35 \mathrm{~V}$ vs $\mathrm{RHE}$. In comparison, Pourbaix diagrams for $\mathrm{Mn}$ and Fe oxides show that the stability windows are $0.49-1.32$ $\mathrm{V}$ vs RHE and $0.10-1.57 \mathrm{~V}$ vs RHE, respectively, while Co and Ni oxides are only stable as hydroxides well above the ORR potential window (Figure S15). Thus, the antimonate framework increases the thermodynamic stability of the oxide within the potential region of interest for the ORR for $\mathrm{Mn}, \mathrm{Co}$, and $\mathrm{Ni}$, while maintaining the stability of $\mathrm{Fe}$. Experimentally, the antimonates exhibit minimal redox features in the $0.05-1.0 \mathrm{~V}$ vs RHE regime, suggesting that the catalysts themselves are not undergoing significant oxidation or reduction (Figure S16). The stabilization of the $\mathrm{Mn}^{2+}$ oxidation state in the antimonate is particularly interesting in comparison to the transformations observed for the oxide. ${ }^{54}$ The stability windows indicate that these first-row transition metal 
antimonates are expected to be stable in alkaline electrolyte under the ORR testing conditions utilized in this study.
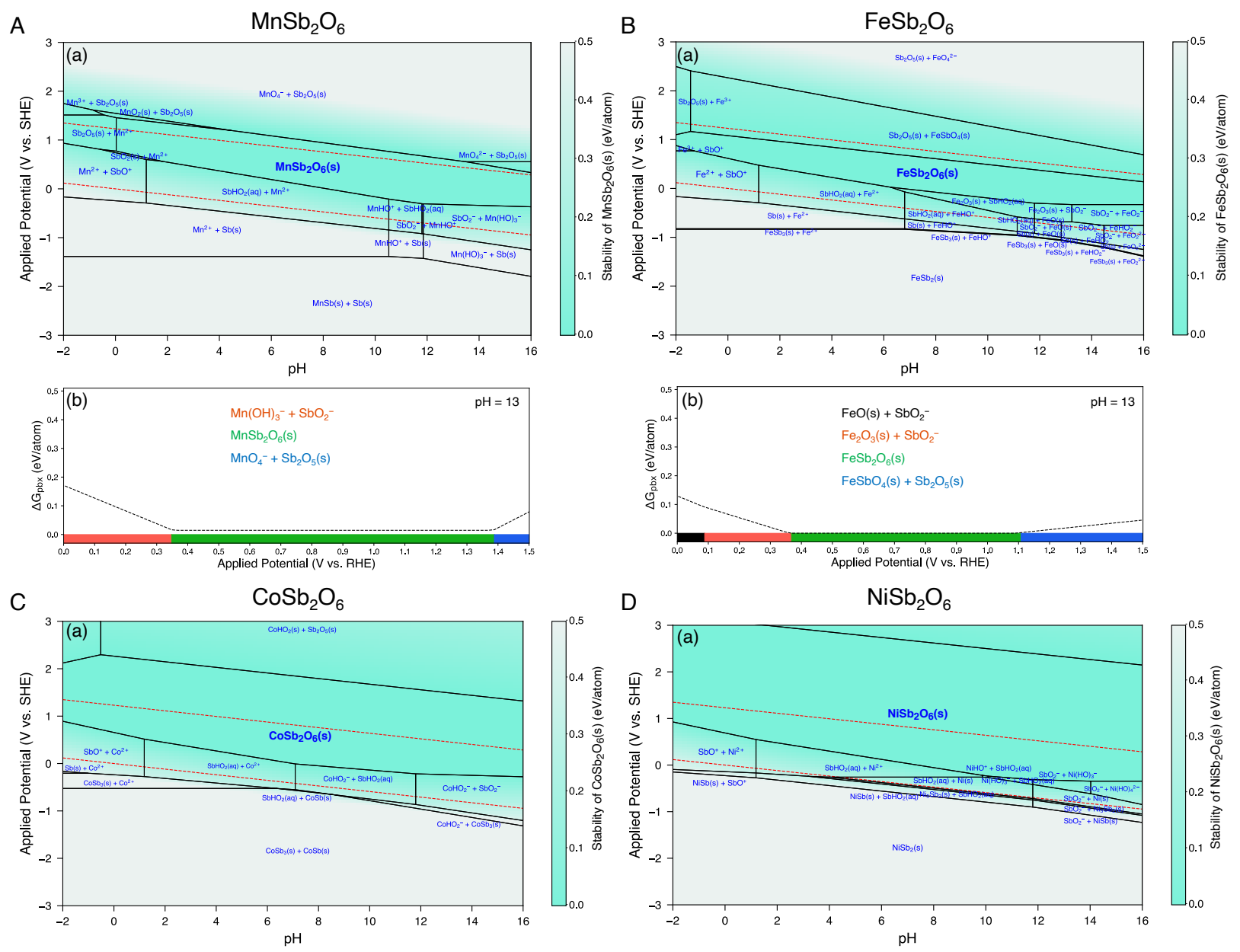

$\mathrm{D}$
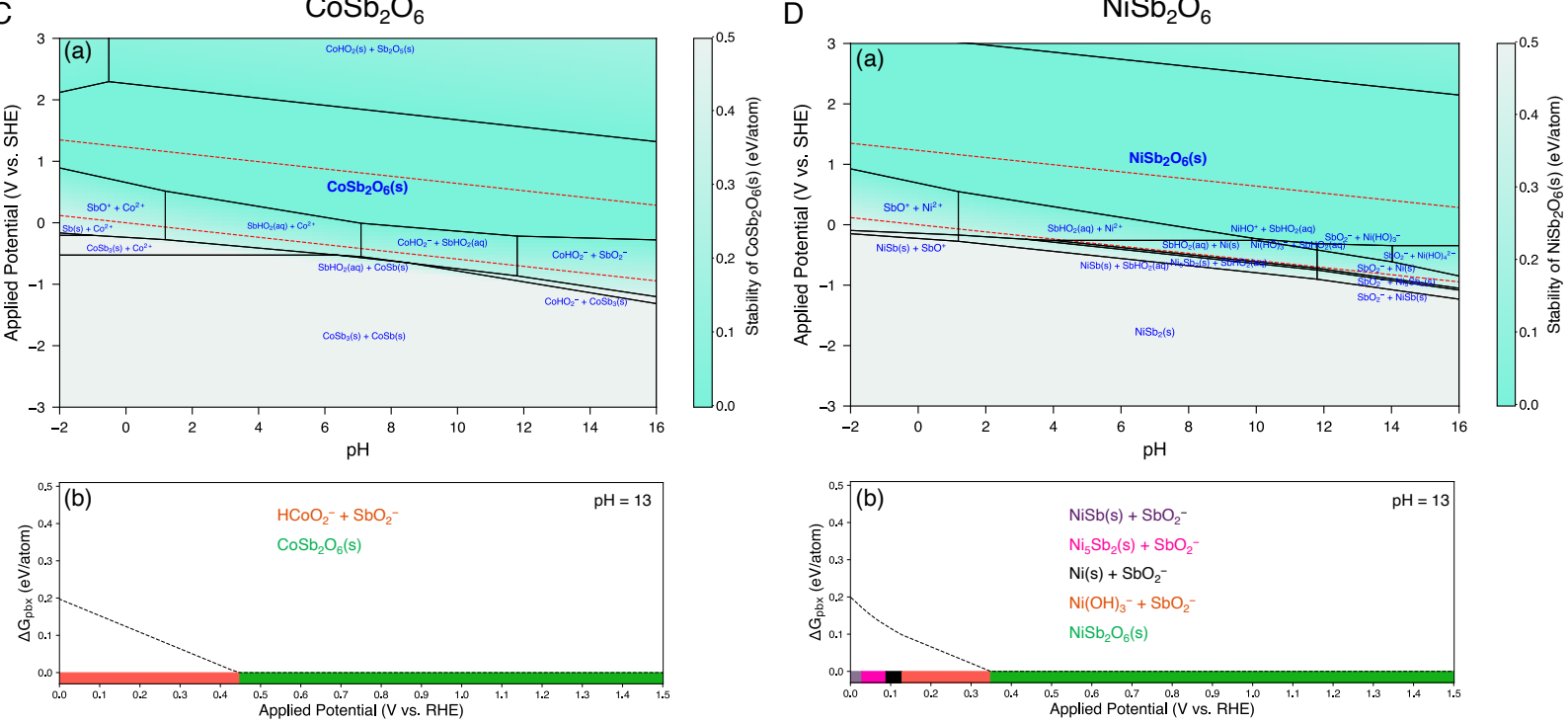

Figure 5. Pourbaix diagrams of metal antimonates Pourbaix diagrams constructed with aqueous ion concentrations $10^{-6} \mathrm{M}$ at $25^{\circ} \mathrm{C}$ for the $\mathrm{M}-\mathrm{Sb}-\mathrm{O}-\mathrm{H}_{2} \mathrm{O}$ phases where $\mathrm{M}$ $=(\mathbf{A}) \mathrm{Mn},(\mathbf{B}) \mathrm{Fe},(\mathbf{C}) \mathrm{Co}$, and (D) Ni. Color bar on the right of each graph indicates the relative stability of the antimonate phases (green $=$ more stable, gray $=$ less stable). Dashed red lines are the equilibrium potentials for oxygen (Eо2/H2O $\left.=1.23 \mathrm{~V}_{\mathrm{RHE}}\right)$ and hydrogen $\left(\mathrm{E}_{\mathrm{H}+\mathrm{H} 2}=0.00 \mathrm{~V}_{\mathrm{RHE}}\right)$ electrochemistry. Subplots show the stable phases over 0 $-1.5 \mathrm{~V}$ vs $\mathrm{RHE}$ at $\mathrm{pH} 13$. 
Experimentally, we approach stability from two, interconnected perspectives: the retention or loss of electrochemical performance and the material stability, including any changes to morphology, structure, and composition. To assess stability under conditions that place comparable demands on the catalyst material, a $5 \mathrm{~h}$ chronopotentiometry (CP) experiment at $1 \mathrm{~mA} \mathrm{~cm}{ }^{-2}$ geo was utilized. The change in the overpotential needed to maintain this current density at the beginning and end of the $5 \mathrm{~h}$ test is shown for the 4 antimonates and pure oxides in Figure 6A. Most catalysts show loss of performance with small increases $(<70 \mathrm{mV})$ in overpotential during the $5 \mathrm{~h} \mathrm{CP}$, while $\mathrm{MnSb}_{2} \mathrm{O}_{6}, \mathrm{Mn}_{2} \mathrm{O}_{3}$, and $\mathrm{Co}_{3} \mathrm{O}_{4}$ show improved performance with small decreases in overpotential. Mass activity is generally shown to increase or remain constant after testing (as measured by several $\mathrm{CV}$ cycles before and after the $5 \mathrm{~h} \mathrm{CP}$ ), indicating that activity is recoverable with cycling (Figure 6B, S17). Only $\mathrm{CoSb}_{2} \mathrm{O}_{6}, \mathrm{FeO}_{x}$, and $\mathrm{NiO}$ had lower mass activity after stability testing, decreasing by $15 \%, 25 \%$, and $50 \%$ at $0.7 \mathrm{~V}$ vs RHE, respectively.

A

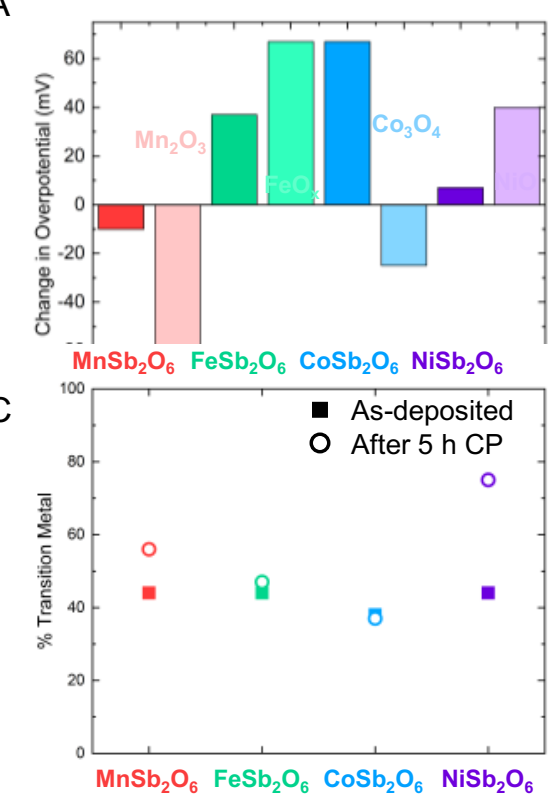

B

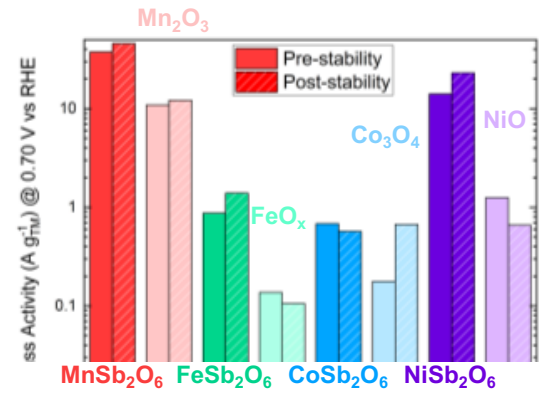

D

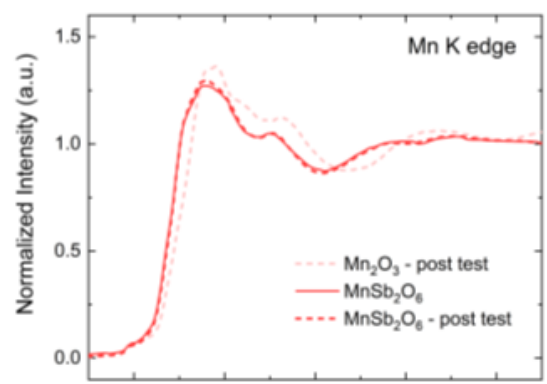

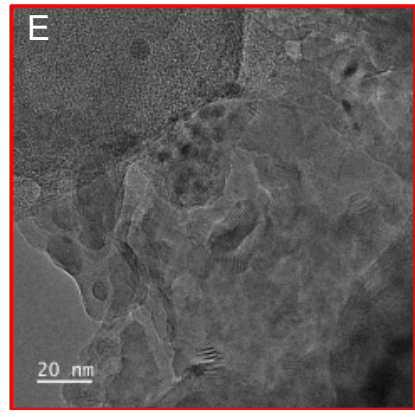
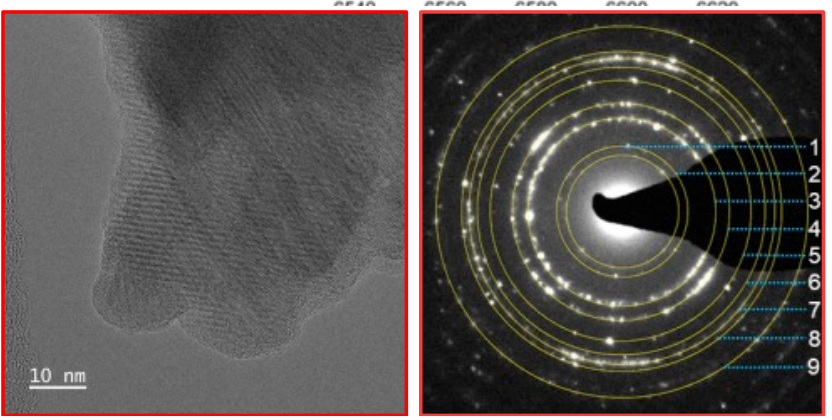
Figure 6. Electrochemical and material analysis of antimonate stability $5 \mathrm{~h}$ chronopotentiometry measurements of catalysts at $1 \mathrm{~mA} \mathrm{~cm}-2$ geo in $0.1 \mathrm{M} \mathrm{KOH}$ were conducted. (A) Change in overpotential during the stability test and (B) mass activity at $0.7 \mathrm{~V}$ vs $\mathrm{RHE}$ before (solid bar) and after the stability test (slashed bar) for $\mathrm{MnSb}_{2} \mathrm{O}_{6}$ (red), $\mathrm{Mn}_{2} \mathrm{O}_{3}$ (pink), $\mathrm{FeSb}_{2} \mathrm{O}_{6}$ (green), $\mathrm{FeO}_{x}$ (light green), $\mathrm{CoSb}_{2} \mathrm{O}_{6}$ (blue), $\mathrm{Co}_{3} \mathrm{O}_{4}$ (light blue), $\mathrm{NiSb}_{2} \mathrm{O}_{6}$ (purple), and $\mathrm{NiO}$ (light purple) catalysts. (C) Transition metal molar percentage before and after the stability test for the antimonates from XPS. (D) Mn K-edge XAS spectra of $\mathrm{MnSb}_{2} \mathrm{O}_{6}$ before and after the stability test, in comparison with $\mathrm{Mn}_{2} \mathrm{O}_{3}$ after the stability test (pink). (E) HR-TEM images and SADP analysis of the $\mathrm{MnSb}_{2} \mathrm{O}_{6}$ catalyst after the $5 \mathrm{~h}$ stability test.

To understand the material changes that may occur during electrocatalytic testing, several materials characterization methods were used. XPS analysis of the films after the $5 \mathrm{~h}$ CP experiment shows small to no changes in the transition metal molar percentage (of transition metal $+\mathrm{Sb}$ ) for $\mathrm{Mn}$, $\mathrm{Fe}$, and $\mathrm{Co}$, while there is a significant increase in surface $\mathrm{Ni}$ content after testing (Figure $\mathbf{6 C}$ ). This indicates an enrichment in $\mathrm{Ni}$ at the surface of the catalyst after testing, perhaps due to the formation of surface hydroxide or oxyhydroxide species as indicated by shifts to higher binding energies in the Ni $2 p$ spectra (Figure S18), as has been reported frequently in the literature. ${ }^{55,56}$ Quantification of $\mathrm{Fe}$ content after testing was based on the Fe 3p spectra because of strong overlap of the Fe $2 p$ with $F$ 1s signal. The Fe 3p spectra show minimal shifts with testing, with the pretest and posttest samples corresponding to $\mathrm{Fe}_{2} \mathrm{O}_{3}$. The transition metal $2 p$ spectra after testing show insignificant changes for $\mathrm{MnSb}_{2} \mathrm{O}_{6}$ and $\mathrm{CoSb}_{2} \mathrm{O}_{6}$ compared to the pre-test, indicating that the nature of the active site is not changing with testing (Figure S18). Mn $\mathrm{K}$-edge XAS of the $\mathrm{MnSb}_{2} \mathrm{O}_{6}$ before and after testing shows little change in white line intensity or edge position, with both edges at a distinctly lower energy than the $\mathrm{Mn}_{2} \mathrm{O}_{3}$ reference (Figure 6D). This indicates that the $\mathrm{MnSb}_{2} \mathrm{O}_{6}$ remains at a lower oxidation state than the 3+ present in $\mathrm{Mn}_{2} \mathrm{O}_{3} .{ }^{57}$ Finally, Figure 6E shows HRTEM images and SADP of the $\mathrm{MnSb}_{2} \mathrm{O}_{6}$ nanoparticles after testing. The particles are observed to have retained their size, shape, and crystallinity, with the SADP showing expected peaks for the rutile structure at $0.239,0.199,0.170$, and $0.163 \mathrm{~nm}$ (Table S1). STEM-EDS mapping of $O$, $\mathrm{Sb}$, and $\mathrm{Mn}$ for the $\mathrm{MnSb}_{2} \mathrm{O}_{6}$ before and after testing in Figure $\mathrm{S} 19$ shows that the elements are generally evenly distributed across the particle, though areas of low $\mathrm{Mn}$ or $\mathrm{Sb}$ concentration may correlate to minority $\mathrm{Mn}_{2} \mathrm{O}_{3}$ or $\mathrm{Sb}_{2} \mathrm{O}_{4}$ phases observed by XRD. The elements remain well-distributed after testing, indicating that the particles are stable. Overall, we conclude that the catalysts, and particularly $\mathrm{MnSb}_{2} \mathrm{O}_{6}$, are substantially stable materially and electrocatalytically in alkaline conditions. 
Neither the antimonates nor the oxides show appreciable ORR activity in acidic media (Figure S20). However, it is still important to understand their material stability under these conditions and whether the antimonate provides a stabilizing framework, as was hypothesized. Pourbaix analysis at $\mathrm{pH} 1$ shows that the antimonates are expected to be stable in the ORR potential window at $0.6 \mathrm{~V}$ vs RHE and above (Figure S21). To probe this experimentally, the catalysts were held at $0.6 \mathrm{~V}$ vs $\mathrm{RHE}$ for $5 \mathrm{~h}$ chronoamperometry experiments in $0.1 \mathrm{M} \mathrm{HClO}_{4}$. While inductively coupled plasma - mass spectrometry (ICPMS) would provide the most accurate information about material stability, this measurement was not possible due to the difficulty of dissolving Sb. Therefore, XPS was used to analyze both the TM:Sb ratio and changes in TM oxidation state (Figure S22). After testing, $\mathrm{MnSb}_{2} \mathrm{O}_{6}$ shows a decrease in $\mathrm{Mn}$ content, while $\mathrm{FeSb}_{2} \mathrm{O}_{6}$ and $\mathrm{CoSb}_{2} \mathrm{O}_{6}$ show small increases in $\mathrm{Fe}$ and $\mathrm{Co}$ content and $\mathrm{NiSb}_{2} \mathrm{O}_{6}$ shows a large increase in $\mathrm{Ni}$ content. This surface transition metal enrichment for $\mathrm{Fe}$, Co, and $\mathrm{Ni}$ may indicate the formation of Sb-poor hydroxide or oxyhydroxide surface species with testing. The high resolution $\mathrm{Mn} 2 \mathrm{p}$ spectrum for $\mathrm{MnSb}_{2} \mathrm{O}_{6}$ shows very little change after testing in acid, while $\mathrm{Mn}_{2} \mathrm{O}_{3}$ exhibits a shift to a higher binding energy (Figure S18). The Fe 3p spectra show minimal changes for either $\mathrm{FeSb}_{2} \mathrm{O}_{6}$ or $\mathrm{FeO}_{x}$ with testing. The $\mathrm{Co} 2 \mathrm{p}$ spectrum for $\mathrm{CoSb}_{2} \mathrm{O}_{6}$ shows a shift to higher binding energies, in support of the hypothesis of formation of a surface (oxy)hydroxide, while the $\mathrm{Co}_{3} \mathrm{O}_{4}$ has negligible $\mathrm{Co}$ signal; this shows an enhancement of stability with the antimony framework. This corresponds well with the increased stability window predicted by the Pourbaix diagrams for Co antimonate compared to the oxide at $\mathrm{pH} 1$ (Figures S15,21). Finally, the Ni $2 \mathrm{p}$ spectra for both $\mathrm{NiSb}_{2} \mathrm{O}_{6}$ and $\mathrm{NiO}$ show a change in shape and position of the peaks, indicating significant changes to the surface composition. The overall retention of composition and oxidation state of the antimonates in acidic conditions, with spectra comparable to those from the alkaline stability test, indicates promising stability, including an enhancement of stability for Co in the antimony framework.

In this section we have investigated the ORR performance of the transition metal antimonate catalysts in comparison with the corresponding transition metal and $\mathrm{Sb}$ oxides. In agreement with theoretical calculations, the four antimonates demonstrated promising activity and stability for the alkaline oxygen reduction reaction, with $\mathrm{Mn}$ antimonate showing the highest performance. Furthermore, Pourbaix analysis indicating electrochemical stability at ORR-relevant potentials is supported by electrocatalytic and material stability characterization in alkaline and acidic electrolytes. The distinct activity, selectivity, and stability profiles observed for the first-row transition metal antimonates relative to the oxides indicate that the antimonate framework plays an important role in determining catalyst performance. 


\section{Conclusions}

In this work, we highlight a combined theory and experiment approach to the discovery and application of novel electrocatalytic materials for the ORR. Theoretically, we found that first-row transition metal antimonates are promising ORR catalysts with good oxygen binding energetics, conductivity, and stability and highlight $\mathrm{MnSb}_{2} \mathrm{O}_{6}$ as a particularly interesting candidate for experimental testing. Experimentally, the antimonate is found to provide a framework for tuning the activity of the transition metal oxide active site, as $\mathrm{Mn}$, $\mathrm{Fe}$, Co, and $\mathrm{Ni}$ antimonates showed intrinsic mass activity improvements over the analogously synthesized transition metal oxides. In agreement with theoretical calculations, the $\mathrm{MnSb}_{2} \mathrm{O}_{6}$ catalyst had the highest ORR mass and specific activity. The $\mathrm{NiSb}_{2} \mathrm{O}_{6}$ catalyst showed the most significant impact of the antimonate framework, with a large increase in $2 \mathrm{e}^{-}$selectivity compared to $\mathrm{NiO}$. Pourbaix analysis was used to identify the $\mathrm{pH}$-voltage windows of stability for the transition metal antimonates, including substantial increases in the stable voltage window for $\mathrm{Co}$ and $\mathrm{Ni}$ in the antimonate structure compared to the oxides at $\mathrm{pH} 13 \quad \mathrm{MnSb}_{2} \mathrm{O}_{6}$ demonstrated significant electrochemical and material stability, as measured by a $10 \mathrm{mV}$ improvement (decrease) in overpotential and only $10 \%$ loss of Mn over the course of a $5 \mathrm{~h}$ chronopotentiometry experiment in $0.1 \mathrm{M} \mathrm{KOH}$, with no significant changes in morphology, structure, or composition. This stabilizing, conductive antimony oxide framework will be of interest for a variety of electrocatalytic applications.

\section{Acknowledgments}

This work was supported by the Toyota Research Institute through the Accelerated Materials Design and Discovery program. Part of this work was performed at the Stanford Nano Shared Facilities (SNSF) and the Stanford Nanofabrication Facility (SNF), supported by the National Science Foundation under Award ECCS-2026822. Use of the Stanford Synchrotron Radiation Lightsource, SLAC National Accelerator Laboratory, is supported by the U.S. DoE, Office of BES under Contract No. DE-AC02-76SF00515. 


\section{References}

(1) Chu, S.; Majumdar, A. Opportunities and Challenges for a Sustainable Energy Future. Nature 2012, 488 (7411), 294-303.

(2) Debe, M. K. Electrocatalyst Approaches and Challenges for Automotive Fuel Cells. Nature 2012, 486 (7401), 43-51.

(3) Wu, J.; Yang, H. Platinum-Based Oxygen Reduction Electrocatalysts. Acc. Chem. Res. 2013, 46 (8), 1848-1857.

(4) Shao, M.; Chang, Q.; Dodelet, J. P.; Chenitz, R. Recent Advances in Electrocatalysts for Oxygen Reduction Reaction. Chem. Rev. 2016, 116 (6), 3594-3657.

(5) Seh, Z. W.; Kibsgaard, J.; Dickens, C. F.; Chorkendorff, I.; Nørskov, J. K.; Jaramillo, T. F. Combining Theory and Experiment in Electrocatalysis: Insights into Materials Design. Science 2017, 355 (6321), eaad4998.

(6) Chen, Z.; Higgins, D.; Yu, A.; Zhang, L.; Zhang, J. A Review on Non-Precious Metal Electrocatalysts for PEM Fuel Cells. Energy Environ. Sci. 2011, 4 (9), 3167-3192.

(7) Ge, X.; Sumboja, A.; Wuu, D.; An, T.; Li, B.; Goh, F. W. T.; Hor, T. S. A.; Zong, Y.; Liu, Z. Oxygen Reduction in Alkaline Media: From Mechanisms to Recent Advances of Catalysts. ACS Catal. 2015, 5 (8), 4643-4667.

(8) Xia, W.; Mahmood, A.; Liang, Z.; Zou, R.; Guo, S. Earth-Abundant Nanomaterials for Oxygen Reduction. Angew. Chemie - Int. Ed. 2016, 55 (8), 2650-2676.

(9) Banham, D.; Ye, S.; Pei, K.; Ozaki, J.; Kishimoto, T.; Imashiro, Y. A Review of the Stability and Durability of Non-Precious Metal Catalysts for the Oxygen Reduction Reaction in Proton Exchange Membrane Fuel Cells. J. Power Sources 2015, 285, 334348.

(10) Kumar, K.; Dubau, L.; Mermoux, M.; Li, J.; Zitolo, A.; Nelayah, J.; Jaouen, F.; Maillard, F. On the Influence of Oxygen on the Degradation of Fe-N-C Catalysts. Angew. Chemie Int. Ed. 2020, 59 (8), 3235-3243.

(11) Su, H. Y.; Gorlin, Y.; Man, I. C.; Calle-Vallejo, F.; K., N. J.; Jaramillo, T. F.; Rossmeisl, J. Identifying Active Surface Phases for Metal Oxide Electrocatalysts: A Study of Manganese Oxide Bi-Functional Catalysts for Oxygen Reduction and Water Oxidation Catalysis. Phys. Chem. Chem. Phys. 2012, 14 (40), 14010-14022.

(12) Stoerzinger, K. A.; Risch, M.; Han, B.; Shao-Horn, Y. Recent Insights into Manganese Oxides in Catalyzing Oxygen Reduction Kinetics. ACS Catal. 2015, 5 (10), 6021-6031.

(13) Guan, C.; Sumboja, A.; Wu, H.; Ren, W.; Liu, X.; Zhang, H.; Liu, Z.; Cheng, C.; Pennycook, S. J.; Wang, J. Hollow Co3O4 Nanosphere Embedded in Carbon Arrays for Stable and Flexible Solid-State Zinc-Air Batteries. Adv. Mater. 2017, 29 (44), 1-9.

(14) Li, H.; Kelly, S.; Guevarra, D.; Wang, Z.; Wang, Y.; Haber, J. A.; Anand, M.; Gunasooriya, G. T. K. K.; Abraham, C. S.; Vijay, S.; Gregoire, J. M.; Nørskov, J. K. Analysis of the Limitations in the Oxygen Reduction Activity of Transition Metal Oxide Surfaces. Nat. Catal. 2021, 4, 463-468.

(15) Hong, W. T.; Risch, M.; Stoerzinger, K. A.; Grimaud, A.; Suntivich, J.; Shao-Horn, Y. 
Toward the Rational Design of Non-Precious Transition Metal Oxides for Oxygen Electrocatalysis. Energy \& Environmental Science. Royal Society of Chemistry May 6, 2015, pp 1404-1427.

(16) Shinde, A.; Jones, R. J. R.; Guevarra, D.; Mitrovic, S.; Becerra-Stasiewicz, N.; Haber, J. A.; Jin, J.; Gregoire, J. M. High-Throughput Screening for Acid-Stable Oxygen Evolution Electrocatalysts in the (Mn-Co-Ta-Sb)Ox Composition Space. Electrocatalysis 2015, 6 (2), 229-236.

(17) Moreno-Hernandez, I. A.; Macfarland, C. A.; Read, C. G.; Papadantonakis, K. M.; Brunschwig, B. S.; Lewis, N. S. Crystalline Nickel Manganese Antimonate as a Stable Water-Oxidation Catalyst in Aqueous 1.0 M H2SO4. Energy Environ. Sci. 2017, 10 (10), 2103-2108.

(18) Zhou, L.; Shinde, A.; Montoya, J. H.; Singh, A.; Gul, S.; Yano, J.; Ye, Y.; Crumlin, E. J.; Richter, M. H.; Cooper, J. K.; Stein, H. S.; Haber, J. A.; Persson, K. A.; Gregoire, J. M. Rutile Alloys in the Mn-Sb-O System Stabilize Mn 3+ to Enable Oxygen Evolution in Strong Acid. ACS Catal. 2018, 8 (12), 10938-10948.

(19) Evans, T. A.; Choi, K. S. Electrochemical Synthesis and Investigation of Stoichiometric, Phase - Pure CoSb2O6 and MnSb2O6 Electrodes for the Oxygen Evolution Reaction in Acidic Media. ACS Appl. Energy Mater. 2020, 3 (6), 5563-5571.

(20) Wang, Z.; Zheng, Y.-R.; Chorkendorff, I.; Nørskov, J. K. Acid-Stable Oxides for Oxygen Electrocatalysis. ACS Energy Lett. 2020, 5 (9), 2905-2908.

(21) Gunasooriya, G. T. K. K.; Nørskov, J. K. Analysis of Acid-Stable and Active Oxides for the Oxygen Evolution Reaction. ACS Energy Lett. 2020, 5 (12), 3778-3787.

(22) Hammer, B.; Hansen, L. B.; Nørskov, J. K. Improved Adsorption Energetics within Density-Functional Theory Using Revised Perdew-Burke-Ernzerhof Functionals. Phys. Rev. B - Condens. Matter Mater. Phys. 1999, 59 (11), 7413-7421.

(23) Kresse, G.; Furthmüller, J. Efficient Iterative Schemes for Ab Initio Total-Energy Calculations Using a Plane-Wave Basis Set. Phys. Rev. B - Condens. Matter Mater. Phys. 1996, 54 (16), 11169-11186.

(24) Kresse, G.; Furthmüller, J. Efficiency of Ab-Initio Total Energy Calculations for Metals and Semiconductors Using a Plane-Wave Basis Set. Comput. Mater. Sci. 1996, 6 (1), 15-50.

(25) Jain, A.; Ong, S. P.; Hautier, G.; Chen, W.; Richards, W. D.; Dacek, S.; Cholia, S.; Gunter, D.; Skinner, D.; Ceder, G.; Persson, K. A. Commentary: The Materials Project: A Materials Genome Approach to Accelerating Materials Innovation. APL Mater. 2013, 1 (1), 011002.

(26) Ong, S. P.; Richards, W. D.; Jain, A.; Hautier, G.; Kocher, M.; Cholia, S.; Gunter, D.; Chevrier, V. L.; Persson, K. A.; Ceder, G. Python Materials Genomics (Pymatgen): A Robust, Open-Source Python Library for Materials Analysis. Comput. Mater. Sci. 2013, 68, 314-319.

(27) Hjorth Larsen, A.; Jørgen Mortensen, J.; Blomqvist, J.; Castelli, I. E.; Christensen, R.; Dułak, M.; Friis, J.; Groves, M. N.; Hammer, B.; Hargus, C.; Hermes, E. D.; Jennings, P. C.; Bjerre Jensen, P.; Kermode, J.; Kitchin, J. R.; Leonhard Kolsbjerg, E.; Kubal, J.; 
Kaasbjerg, K.; Lysgaard, S.; Bergmann Maronsson, J.; Maxson, T.; Olsen, T.; Pastewka, L.; Peterson, A.; Rostgaard, C.; Schiøtz, J.; Schütt, O.; Strange, M.; Thygesen, K. S.; Vegge, T.; Vilhelmsen, L.; Walter, M.; Zeng, Z.; Jacobsen, K. W. The Atomic Simulation Environment-a Python Library for Working with Atoms. J. Phys. Condens. Matter 2017, 29 (27), 273002.

(28) Nørskov, J. K.; Rossmeisl, J.; Logadottir, A.; Lindqvist, L.; Kitchin, J. R.; Bligaard, T.; Jónsson, $\mathrm{H}$. Origin of the Overpotential for Oxygen Reduction at a Fuel-Cell Cathode. J. Phys. Chem. B 2004, 108 (46), 17886-17892.

(29) Guillén-Bonilla, H.; Rodríguez-Betancourtt, V.-M.; Guillen-Bonilla, J. T.; Gildo-Ortiz, L.; Guillen-Bonilla, A.; Casallas-Moreno, Y. L.; Blanco-Alonso, O.; Reyes-Gómez, J. Sensitivity Tests of Pellets Made from Manganese Antimonate Nanoparticles in Carbon Monoxide and Propane Atmospheres. Sensors . 2018.

(30) Ravel, B.; Newville, M. ATHENA, ARTEMIS, HEPHAESTUS: Data Analysis for X-Ray Absorption Spectroscopy Using IFEFFIT. J. Synchrotron Radiat. 2005, 12 (4), 537-541.

(31) Newville, M. Larch: An Analysis Package for XAFS and Related Spectroscopies. J. Phys. Conf. Ser. 2013, 430, 12007.

(32) De Vrieze, J. E.; Gunasooriya, G. K. K.; Thybaut, J. W.; Saeys, M. Operando Computational Catalysis: Shape, Structure, and Coverage under Reaction Conditions. Curr. Opin. Chem. Eng. 2019, 23, 85-91.

(33) Hansen, H. A.; Rossmeisl, J.; Nørskov, J. K. Surface Pourbaix Diagrams and Oxygen Reduction Activity of Pt, Ag and Ni(111) Surfaces Studied by DFT. Phys. Chem. Chem. Phys. 2008, 10 (25), 3722-3730.

(34) Kulkarni, A.; Siahrostami, S.; Patel, A.; Nørskov, J. K. Understanding Catalytic Activity Trends in the Oxygen Reduction Reaction. Chemical Reviews. American Chemical Society March 14, 2018, pp 2302-2312.

(35) López-Garzón, F. J.; Domingo-García, M.; Pérez-Mendoza, M.; Alvarez, P. M.; GómezSerrano, V. Textural and Chemical Surface Modifications Produced by Some Oxidation Treatments of a Glassy Carbon. Langmuir 2003, 19 (7), 2838-2844.

(36) Sun, S.; Li, H.; Xu, Z. J. Impact of Surface Area in Evaluation of Catalyst Activity. Joule 2018, 2 (6), 1024-1027.

(37) NIST Inorganic Crystal Structure Database, NIST Standard Reference Database Number 3, National Institute of Standards and Technology, Gaithersburg MD, 20899.

(38) NIST X-ray Photoelectron Spectroscopy Database, NIST Standard Reference Database 20, National Institute of Standards and Technology, Gaithersburg MD, 20899 (2000).

(39) Rockenberger, J.; Zum Felde, U.; Tischer, M.; Tröger, L.; Haase, M.; Weller, H. Near Edge X-Ray Absorption Fine Structure Measurements (XANES) and Extended x-Ray Absorption Fine Structure Measurements (EXAFS) of the Valence State and Coordination of Antimony in Doped Nanocrystalline SnO2. J. Chem. Phys. 2000, 112 (9), 4296-4304.

(40) Durand, J.-M.; Lippens, P. E.; Olivier-Fourcade, J.; Jumas, J.-C.; Womes, M. Sb LIIIEdge XAS Study of the Ternary System Sb2S3-As2S3-TI2S. J. Non. Cryst. Solids 1996, 194 (1), 109-121. 
(41) Kilias, S. P.; Gousgouni, M.; Godelitsas, A.; Gamaletsos, P.; Mertzimekis, T. J.; Nomikou, P.; Argyraki, A.; Goettlicher, J.; Steininger, R.; Papanikolaou, D. Antimony Fixation In Solid Phases At The Hydrothermal Field Of Kolumbo Submarine Arc-Volcano (Santorini): Deposition Model And Environmental Implications. Bull. Geol. Soc. Greece 2016, 50 (4), 2200-2209.

(42) Xi, L.; Schwanke, C.; Xiao, J.; Abdi, F. F.; Zaharieva, I.; Lange, K. M. In Situ L-Edge XAS Study of a Manganese Oxide Water Oxidation Catalyst. J. Phys. Chem. C 2017, 121 (22), 12003-12009.

(43) Crocombette, J. P.; Pollak, M.; Jollet, F.; Thromat, N.; Gautier-Soyer, M. X-RayAbsorption Spectroscopy at the Fe L2,3 Threshold in Iron Oxides. Phys. Rev. B 1995, 52 (5), 3143-3150.

(44) Leveneur, J.; Waterhouse, G. I. N.; Kennedy, J.; Metson, J. B.; Mitchell, D. R. G. Nucleation and Growth of Fe Nanoparticles in SiO2: A TEM, XPS, and Fe L-Edge XANES Investigation. J. Phys. Chem. C 2011, 115 (43), 20978-20985.

(45) Bora, D. K.; Cheng, X.; Kapilashrami, M.; Glans, P. A.; Luo, Y.; Guo, J. H. Influence of Crystal Structure, Ligand Environment and Morphology on Co L-Edge XAS Spectral Characteristics in Cobalt Compounds. J. Synchrotron Radiat. 2015, 22, 1450-1458.

(46) Morales, F.; De Groot, F. M. F.; Glatzel, P.; Kleimenov, E.; Bluhm, H.; Hävecker, M.; Knop-Gericke, A.; Weckhuysen, B. M. In Situ X-Ray Absorption of Co/Mn/TiO 2 Catalysts for Fischer-Tropsch Synthesis. J. Phys. Chem. B 2004, 108 (41), 16201-16207.

(47) Bazin, D.; Kovács, I.; Guczi, L.; Parent, P.; Laffon, C.; De Groot, F.; Ducreux, O.; Lynch, J. Genesis of Co/SiO2 Catalysts: XAS Study at the Cobalt LIII,II Absorption Edges. J. Catal. 2000, 189 (2), 456-462.

(48) Al Samarai, M.; Hahn, A. W.; Beheshti Askari, A.; Cui, Y. T.; Yamazoe, K.; Miyawaki, J.; Harada, Y.; Rüdiger, O.; Debeer, S. Elucidation of Structure-Activity Correlations in a Nickel Manganese Oxide Oxygen Evolution Reaction Catalyst by Operando Ni L-Edge XRay Absorption Spectroscopy and 2p3d Resonant Inelastic X-Ray Scattering. ACS Appl. Mater. Interfaces 2019, 11 (42), 38595-38605.

(49) Meng, Y.; Song, W.; Huang, H.; Ren, Z.; Chen, S.-Y.; Suib, S. L. Structure-Property Relationship of Bifunctional MnO2 Nanostructures: Highly Efficient, Ultra-Stable Electrochemical Water Oxidation and Oxygen Reduction Reaction Catalysts Identified in Alkaline Media. J. Am. Chem. Soc. 2014, 136 (32), 11452-11464.

(50) Assumpção, M. H. M. T.; Moraes, A.; De Souza, R. F. B.; Gaubeur, I.; Oliveira, R. T. S.; Antonin, V. S.; Malpass, G. R. P.; Rocha, R. S.; Calegaro, M. L.; Lanza, M. R. V; Santos, M. C. Low Content Cerium Oxide Nanoparticles on Carbon for Hydrogen Peroxide Electrosynthesis. Appl. Catal. A Gen. 2012, 411-412, 1-6.

(51) Carneiro, J. F.; Paulo, M. J.; Siaj, M.; Tavares, A. C.; Lanza, M. R. V. Nb2O5 Nanoparticles Supported on Reduced Graphene Oxide Sheets as Electrocatalyst for the H2O2 Electrogeneration. J. Catal. 2015, 332, 51-61.

(52) Perry, S. C.; Pangotra, D.; Vieira, L.; Csepei, L. I.; Sieber, V.; Wang, L.; Ponce de León, C.; Walsh, F. C. Electrochemical Synthesis of Hydrogen Peroxide from Water and Oxygen. Nat. Rev. Chem. 2019, 3 (7), 442-458. 
(53) Persson, K. A.; Waldwick, B.; Lazic, P.; Ceder, G. Prediction of Solid-Aqueous Equilibria: Scheme to Combine First-Principles Calculations of Solids with Experimental Aqueous States. Phys. Rev. B - Condens. Matter Mater. Phys. 2012, 85 (23), 235438.

(54) Speck, F. D.; Santori, P. G.; Jaouen, F.; Cherevko, S. Mechanisms of Manganese Oxide Electrocatalysts Degradation during Oxygen Reduction and Oxygen Evolution Reactions. J. Phys. Chem. C 2019, 123 (41), 25267-25277.

(55) Kreider, M. E.; Gallo, A.; Back, S.; Liu, Y.; Siahrostami, S.; Nordlund, D.; Sinclair, R.; Nørskov, J. K.; King, L. A.; Jaramillo, T. F. Precious Metal-Free Nickel Nitride Catalyst for the Oxygen Reduction Reaction. ACS Appl. Mater. Interfaces 2019, 11 (30), 2686326871.

(56) Liu, J.; Guo, L. In Situ Self-Reconstruction Inducing Amorphous Species: A Key to Electrocatalysis. Matter 2021, 4 (9), 2850-2873.

(57) Sánchez, M. C.; García, J.; Blasco, J.; Subías, G.; Perez-Cacho, J. Local Electronic and Geometrical Structure of LaNi1-XMnxO3+x Perovskites Determined by x-Ray-Absorption Spectroscopy. Phys. Rev. B - Condens. Matter Mater. Phys. 2002, 65 (14), 1-9. 